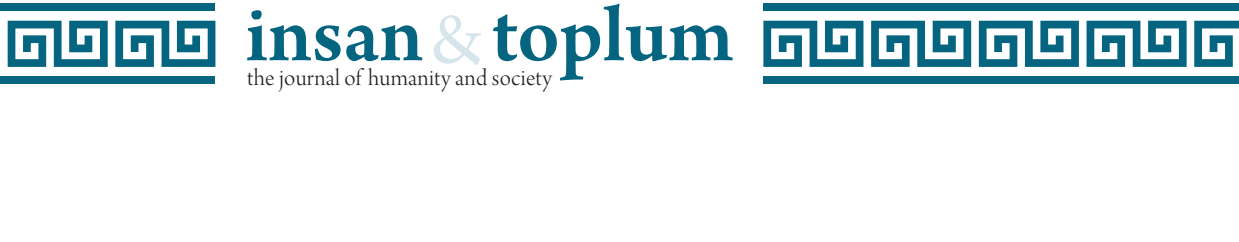

\author{
Handan Akyiğit
}

\begin{abstract}
Öz: Sosyolojide eleştirel kurama yönelik ilginin artmasıyla birlikte milliyetçilik kuramları kendi içerisinde farklı bağlamlarda sorgulanır hâle gelmiştir. Özellikle "temelci" olarak adlandırılan metodolojik milliyetçilik yaklaşımının yöntem ve ilkeleri sorgulanmaktadır. Metodolojik milliyetçiliğin sorgulanmasının sebebi ise temelde pozitivist, ulusa ve tarihe evrenselci bakan, Avrupa merkezci yayılmacı bir anlayışa sahip olmasına bağlanmaktadır. Bu noktada eleştirilerin ortak problemi, özelde toplumsal kültürün ve insan eyleminin göz ardı edilmesine bağlanır. Bu çalışmanın ana temasını metodolojik milliyetçiliğin epistemolojik ve ontolojik kabulleri gereği açmaza düştüğü konular oluşturmaktadır. Bunu yaparken özellikle iki alanın temel kavramlarına başvurulacaktır: Konstrüktivist kuram ve diyalektik bütünsellik. Bu bağlamda metodolojik milliyetçiliğin yetersizliklerini aşabilmek adına yeni bir yöntemin ilkelerinden bahsedilecektir. Öneri olarak tasarlanan yöntemin ilkeleri, Türkiye'de tartışma konusu olan çokkültürlülük olgusu ve kimlik siyasetinin sunmuş olduğu kültür ve toplum tasavvuru bağlamında örneklendirilerek ele alınacaktır. Dolayısıyla bu çalışmanın amacı; milliyetçilik kuramlarına yönelik bir yapıbozumu olmaktan ziyade tarihsel sosyoloji, konstrüktivist duyarlılığın temelinde ilerleyen bir milliyetçilik okumasının yeni perspektiflerin önünü nasıl açabileceğini gösterebilmektir.
\end{abstract}

Anahtar Kelimeler: Diyalektik bütünsellik, halat kültür, konstrüktivist kuram, metodolojik milliyetçilik, tarihsel sosyoloji.

\begin{abstract}
Theories of nationalism have become questionable in their own contexts with increasing interest in critical theory in sociology. Particulalry, the methods and principles of the methodological nationalism approach called as fundamentalist are questioned. The reason for the questioning of methodological nationalism is mainly attributed to its positivist understanding, universalist view of the nation and history and Eurocentric expansionist understanding. A common problem at this point of criticism is connected to the disregard of human action and social culture. The main theme of this study is the issues that methodological nationalism is in a dilemma due to its epistemological and ontological assumptions. By doing this, particular concepts of two areas will be used: constructivist theory and dialectical integrity. In this context, the principles of a new method will be discussed in order to overcome the shortcomings of methodological nationalism. The principles of the proposed method will be exemplified in the context of multiculturalism which is the subject of debate in Turkey and imagination of culture and society presented by identity politics. Therefore, the aim of this study is to show how a reading of nationalism based on historical sociology and constructivist sensibility can pave the way for new perspectives rather than a deconstruction of theories of nationalism.
\end{abstract}

Keywords: Dialectical integrity, rope culture, constructivist theory, methodological nationalism, historical sociology.

(2) Dr. Öğr. Üyesi, Sakarya Üniversitesi. hakyigit@sakarya.edu.tr

(iD) http://orcid.org/0000-0002-7619-1638

(C) İlmi Etüdler Derneği

DOI: 10.12658/M0434.

insan \& toplum, 2021.

insanvetoplum.org
Başvuru: 03.01.20

Revizyon: 25.01.20

Kabul: 18.08.20

Online Basım: 13.10.20 


\section{Giriş}

1990'lı ylların başlarında Yugoslavya'da meydana gelen ve ani bir milliyetçilik patlaması olarak değerlendirilen olayların sonuçları, sosyal bilimlerde küreselleşmenin doğası ve kapsamı hakkındaki ilk karışıklıktan sonra ulus devletin gerilemesi üzerine yapilan tartışmaları tetiklemiştir. Bu tartışmalarda ulus devletin yeniden tanımlanmasını içeren çokkültürcülük konusunun payının büyük olduğu görülmektedir. Çokkültürcülükle birlikte açığa çıkan en önemli konu; "millî kültür" söyleminin sorgulanmasıydı. Çünkü Fukayama'nın (1999) “tarihin sonu dönemine” girdiğimiz önermesinin tersine ulus devletlerde kültürel kimliğe dayalı hak talepleri ekseninde "çokkültürlü ulusdevlet" tartışmaları ve mikro milliyetçilik hareketleri başlamıştır. Bu kültürel kimlik hak talepleri ekseninde gerçekleşen tüm hareketlilikler beraberinde milliyetçiliğin epistemolojik kabullerinin en önemlisi olan ulusal kimlik ve kültür konusunun tartışılmaya açılmasına neden olmuştur. Bu tartışmaların özellikle metodolojik milliyetçiliğin epistemik kabulleriyle geliştirilen çokkültürcü kimlik siyasetine bağlı olarak ele alınması genel bir yaygınlık kazanmıştır. Türkiye de bu sürecin dışında kalmamıştır. Özellikle Batı Avrupa ülkelerinde benzer ölçüde Türkiye'de çokkültürcülük söyleminde millî kültür olgusu; azınlıklar, dinî ve etnik kimlik başta olmak üzere yaygın bir şekilde tartışılmıştır ve bu konuda da birçok çalışma yapılmıştır. Ancak çokkültürcülük söylemi istikrarlı ve güvenli bir dünya kurabilmek için başarılı sonuçlar doğuramamıştır. Özellikle İskoçya, Katalonya ve Quebec'teki etnik temelli milliyetçi hareketlere ve çatışmalara bakıldığında bu açık bir şekilde görülmektedir. Ulus devletler özelinde mikro milliyetçilik bağlamında hareketlenmeler çeşitlenmeye başlamıştır. En güncel haliyle karşılaştığımız bu durum milliyetçilik çalışmalarında metodolojik milliyetçiliğin epistemik kabullerinin sorgulanmasının ve özellikle millî kültür kabulünün temelini oluşturan yanılsamaların açığa çıkartılması gerektiğini göstermektedir.

Bu çalışmanın ana tezi; bu tasavvuru hayata geçirmek için metodolojik milliyetçilik anlayışından sıyrılarak Türkiye özelinde "halat kültür" metaforunun metodolojik bağlamlarını açıklamaktır. Bunu yaparken özellikle iki alanın temel kavramlarına başvurulmuştur: Konstrüktivist kuram ve diyalektik bütünsellik ilkesi. Konstrüktivist kuramın temel kaynaklarından faydalanırken aşılmaya çalışılacak temel konu "metodolojik milliyetçiğin"1 epistemik bağlamları olacaktır. Bu bağlam-

1 Burada özellikle şunu vurgulamak önemlidir. Metodolojik milliyetçilikte 'milliyetçilik' kavramı bir şemsiye terim olarak kullanılmaktadır. Bu şemsiyenin altına ulusal kimlik (ya da milliyet), ulusal bilinç ve onlara dayanan kolektiviteler yani milletler giriyor. Yer yer ulusal kimlik ve ulusal bilincin dayandığ eklemli ideolojiye de gönderme yapmakla birlikte özel olarak belirtilmedikçe bu şemsiyenin altına vatan- 
da metodolojik milliyetçiliğin tarihsel açıdan benzersiz ve milat olarak kabul edilen Batılı konfigürasyonların temelleri ele alınacaktır. Ulus devlet inşa süreçlerinin tarihsel kesinliğine ve yerleşmiş mahiyetine yönelik temel kabul sorgulanacaktır. Batılı ulustan, kültürün yerelliğini gözlerden uzak ve yaygın biçimde yaşamak olarak bahsedilecektir. ${ }^{2}$ Bu yerellik, tarihsellik ${ }^{3}$ hakkında olmaktan ziyade zamanla ve topluluğun kökeniyle ilgilidir. Böylelikle milliyetçiliğin jeopolitik konumlara, özel tarihsel bağlamlara göre özerkleştirilmeye çalışılmasının önemi üzerine perspektif çizilecektir. Dolayısıyla bu çalışmada temel karşıt durulan nokta; ulus kavramının mahiyetinin temel oluşma biçimlerinin modern Batılı ulustan beslenerek tek bir form hâlinde sunulmasıdır.

Diyalektik bütünsellik ilkesinin kaynaklarından faydalanırken ele alınacak temel konu tarihsel analizde dolayısıyla metodolojik milliyetçilikte kültür sorunu olacaktır. Özellikle kültür konusuna eğilmenin temel nedenini son zamanlarda başta Avrupa ülkeleri olmak üzere dünya genelinde millî farklılıkları yeniden ön plana çıkaran ve belirgin bir biçimde ayrımcı bir yolda ilerleyen yeni köktenci tepkiler oluşturmaktadır. Dolayısıyla metodolojik milliyetçilikte kültür sorunu, çokkültürcülük tartışmaları üzerinden örneklerle irdelenecektir. Bu tartışmalar, metodolojik milliyetçiliğin epistemolojik kabulünde yatan ulus fikrinin merkezine yerleştirilen toplumsal ve kültürel tanımlamayla birlikte ifşa edilen "diskursif hitabın”(Bhabha, 2016, s. 265) ${ }^{4}$ karmaşık bağlamlarını gösterecektir.Bu bağlamda metodolojik milliyetçiliğin açmazlarını aşabilmek adına yeni bir yöntemin ilke-

severliğin yabancı düşmanı ve politik olarak eylemci çeşitleri girmemektedir (Greenfeeld, 2017, s. 19). oryantalizm eleştirisi özellikle Edward Said'in (2017) ve Martin Bernal'ın (2016) Avrupamerkezci tarihte 1 rkçılık ve kültürel önyargı meselelerine yönelik yorumların etkisi önemlidir. İkinci aşamada ise Samir Amin'in (2007) ve Eric Wolf'un (2019) ilerlemeci düşünce ve tarih yazımına yönelik çalışmaları ufuk açıcı olmuştur. Bu çalışmaların bütünü Avrupamerkezci perspektifleri eleştirerek sosyal bilimler ve gelişim çalışmalarına dair önemli çıkarımlar sağlamaktadır.

3 Bilindiği üzere modern insanlığın siyasal öznenin temeli Hegel'in açıklamalarına bağlı kalarak okunmaktadır. Bundan dolayı insan bilincinin yeni bir gerçeklik düzeninin ve tarihin ortaya çıkışı 1800'lü yıllara dayandırılarak aktarılmaktadır. Ancak tarih fikrinin Hegel'in ötesinde devam eden bir açılımı vardır. Tarihselliğin başlangıç evrelerinin ve tarihsel bilincin 19. ve 20. yüzyılda yayılışının ve derinleşmesinin hâlâ yazılmamış olan bir tarihi vardır (Gauchet, 2013, ss. 34-35). Bundan dolayı bu çalışmada tarihsellik kavramı parantez içine alınarak ihtiyatlı bir şekilde kullanılmaktadır.

4 Diskurtif hitab neticesinde gelişen stratejiler Certeau'nun (2008, s. 54) ifadesiyle "bir istek öznesi ile erk öznesinin belli bir çevreyle yalıtılmasıyla oluşan güç ilişkilerinin” ölçüldüğü stratejileri (Certeau, 2008, s. 54) içermektedir. Böylelikle halk ve ulus adına işlevde bulunan kültürel kodlar bir dizi toplumsal edebî anlatıların merkezine yerleştirilerek içkin özneler yaratmaktadır. Bu bağlamda çalışmada ulusal kimlik kavramıyla, ulusu oluşturan içkin öznelerin ortak noktası olarak her bir öznenin etnik, bölgesel ve tinsel mülkiyetini tek bir kimlikle birleştirilmesi olarak açıklanarak kavramın sosyolojik bağlamına vurgu yapılmaktadır. 
lerinden bahsedilecektir. Milliyetçilik çalışmalarında öneri olarak tartışılan yeni yöntemin ilkeleri, Türkiye'de çokkültürcü kimlik siyasetinin sunmuş olduğu kültür ve toplum tasavvuru bağlamında örneklendirilerek ele alınacaktır. Aynı zamanda Türkiye'de "halat kültür" kavramıla özdeşleşen siyasallığın ${ }^{5}$ felsefesi üzerine kurulabilecek metodolojik yenilik içeren toplum tasavvuru konusundaki düşünceler öneri niteliğinde ele alınacaktır.

\section{Metodolojik Milliyetçiliğin İki Bağlamı: İlkçi (Primordialist) ve Modern Yaklaşım}

Ulusun ve ulus devletin gerçek doğasını anlamanın ve açıklamanın en iyi yolunun ne olduğu hususundaki tartışmalar son iki yüzyıldır gündemdedir. Bu tartışmaların odak noktasında ise milliyetçilik konusunun önemli bir yeri vardır. Milliyetçilik literatüründeki en dikkat çekici tartışma eksenini milletin ve millî düşüncenin kökenlerine dair sunulan anlatılar oluşturmaktadır. Bu tartışmalarda öncelikli olarak ilkçiler (primordialist) ile modernistleri birbirinden ayrı olarak ele almak gelenekselleşmiştir. Ancak zamanla bu iki yaklaşım kendi içerisinde farklılaşarak girift hâle gelmiştir. Örneğin; 1970'lerden sonra yazılan milliyetçilik kuramlarını inceleyen Özkırımlı (2013, ss. 80-81) özellikle ilkçiler ve modernistler arasındaki görüş ayrılıklarına vurgu yapmıştır. Bu ikili sınıflandırmaya iki kuram arasındaki farklllıklarına bağlı bir ara yol olarak-Anthony Smith'in çalışmalarına atıfta bulunarak- etnosembolcü yaklaşımı eklemiştir.1990'lı yıllardan sonra ise iletişim teknolojilerindeki gelişmeler, sosyal medya kullanımının yaygınlaşması, yeni toplumsal hareketlenmelerin açığa çıkması, başta Orta Doğu'da olmak üzere etnik/dinî çatışmalar nedeniyle göçlerin artması, milliyetçi kuramlarının perspektiflerinin geliştirilmesine yönelik eleştirel tartışmalar kendisini göstermiştir (Szulc,2017;Wallem, 2017 akt. Tekin ve Çemrek, 2020, s. 261).

İlkçi yaklaşım; milliyetçiliğin, insanlığın ilişkisel yaşamında köklü bir yere sahip olduğunu, toplumsal örgütlenmenin kadim, zaruri ve kökleri tarihin

5 Gauchet'un (2013) vurguladığı gibi siyasallık, tarih boyunca kurulmuş tüm toplumları kapsayacak şekilde toplumsal bir aradalığın, toplumsal örgütlenmenin siyasi özünü ifade ederken siyaset, modernite ile birlikte ortaya çıkan demokratik toplumlara özgü siyasi yapıyı dile getirir. Bu yapı içerisinde siyaset, diğer etkinliklerden ayrılmış bir alan olarak bulunur ve toplumun tüm üyelerine açık bir mekanizma olarak işler. Bundan dolayı metodolojik milliyetçiliğe alternatif olarak sunulan yeni metodolojik bakışın temeli siyaset üzerinden değil siyasallık kavramı özelinden ilerlemesinin gerekliliği vurgulanmıştır. Çünkü siyasallık kavramı günümüzde ağırlıklı olarak siyaset özelinden tartışılan milliyetçilik konusunda göz ardı edilen duygu-kimlik, topluluk hayatı, kültür, din, etnik konularıyla birlikte iktisadi, bürokratik, tarihsel göreceliği de içine alan açıklayıcı faktörleri ve nedensel değişkenleri tartışma konusu ederek sentezci analizler sunmamızın önünü açabilecektir. 
derinliklerine kadar uzanan organik bir mevcudiyet olduğunu destekleyebilecek kanıtlar sunmaktadır (Spencer ve Wollman, 2020, s. 56). Daha çok ulus düzeyinde analizlere yönelen ilkçiler, çeşitli milletlerin moderniteden öncede var olduğunu ve milliyetçilik bilincine sahip olduklarını ortaya koymak istemişlerdir (Jensen, 2016, s. 13). İlkçi yaklaşımın kökleri 18. yüzyıl Almanyasını, Herder ve Fichte'nin (1814-1762) ulusun, insanlık durumunun doğal bir parçası olarak çok geçmiş zamandan bu yana varlıklarını koruduklarına yönelik açıklamalarında görülmektedir. Bu çalışmalarda ulusal grubun yaratılış özellikleri; yaşam biçimi, çalışma alışkanlıkları, tutumları, doğal çevresi, iklim ve fiziksel çevresine bağlı olarak ele alınmıştır. 1960'lara kadar ilkçi yaklaşıma dayanan milliyetçilik açıklamalarını, etnik gruplarla ilgili çalışmalardan ayrı ele alınamayacağını ifade eden Özkırımlı (2013, s. 81) özellikle Shils ve Geertz'in çalışmalarına dikkat çekerek terimin etnisite kuramlarından ithal edildiğini ifade eder. İlkçi yaklaşıma dayanan milliyetçilik, çalışmalarını kendi içerisinde üçe ayırır (Özkırımlı, 2013, s. 91): (i) Milletlerin eski çağlardan beri var olduğunu, millî özün tarihî süreçte aynı kaldığını savunan eskilci yaklaşım (Armstrong, 1982, Llobera, 1998); (ii) etnik bağlılıkların kökenini genetik ve içgüdülerde arayan sosyobiyolog ilkçi yaklaşım (van den Berghe), (iii) etnik topluluğu 'öteki'lerden ayırdığına inanan dil, din, ortak geçmiş gibi ögelere bağlılığı ön plana çıkaran kültürel ilkçiler (Geertz, 1973, Shils, 1957).

İlkçilerin aksine milletlerin ve milliyetçiliğin ilk çağdaki köklerini araştırma amacında olmayan modernistlere göre milliyetçilik, nasıl tanımlanırsa tanımlansın sanayileşme/moderniteyle ilişkilidir.Genel itibarıyla modernistler, milliyetçiliğin ilkçi yorumlarının tarih dışı olduğunu çünkü geçmişle olan bağın tamamıyla icat olduğunu iddia etmektedirler. 1960 ve 1970'li yıllara gelindiğinde "modernist" bakış açısı genel geçer öğreti halini alarak tüm ilkçi görüşleri akademiden sildiğini belirten Smith'e (2017, s. 17) göre modernistler, milliyetçilik ideolojisinin ve hareketinin milletlerin yakın tarihli olduğunu ve her ikisinin de küresel olarak toplumların modernlik durumuna geçmesinin ürünü olduğunu öne sürmektedir. Ayrıca milliyetçiliği moderniteyle birlikte ele alan teorisyenlerin birçoğunda ise Weber'in, Durkhem'in ve klasik Marsizmin etkisini görebilmek mümkündür. Milliyetçiliğin tanımına yönelik yapmış oldukları kategoriler doğrultusunda modernistler kendi içinde iki alt başlıkta ele alınabilir: (i) Materyalistler (Gellner, Hobsbawm) ve (ii) kültürcüler (Renan, Anderson).

Materyalist modernistler, milliyetçiliği, sanayileşmenin ve kapitalizmin büyümesinin bir sonucu olarak ele alma eğilimindedirler. Bunların en önemli 
temsilcileri arasında milliyetçiliği geleneksel ve modern toplumlar arasında Weber, Durkheim ve Tönnies'in yaptığı türden bir karşılaştırma yaparak kültür ve sanayileşmeyle birlikte ele alan Ernest Gellner (1992) yer almaktadır. Milliyetçiliği tarım toplumlarında neredeyse tasavvur edilemeyecek bir proje olarak ifade eden Gellner'e (1992) göre sanayileşme sürecini hıll bir şekilde yaşayan Avrupa ülkelerinde millet tasavvuru merkezîleşmeci ve birleştirici bir şekilde Batı'da sorunsuz açığa çıkmıştır. Doğu'ya doğru gidildikçe de modern bir millet ile karşılaşmanın zor olduğunu ifade etmiştir. Çünkü Gellner, milliyetçiliğin varlığını siyasi güce ve bürokratik yönetime borçlu olduğunu ifade eder. Gellner'e göre milliyetçilik, modernitenin bir işlevidir ve modernleşme sürecidir. Modern devletin yapısı olan eğitim, iletişim ve bürokrasi teknolojileri, maniple edici kastlardan ziyade rasyonel, idari zorunluluklar tarafından yönlendirilir. Milletler bu yüzden bu modernleştirici zorunlulukları taşımak için en uygun biçimlerdir. Bu sürecin en temel göstergeleri, Batı Avrupa ülkelerinde kendisini göstermektedir. Benzer bir biçimde Hobsbawm (2014)da milliyetçiliğin kapitalizmin gerekliliklerini yerine getirmek için devlet tarafından icat edildiğini ifade etmektedir. Marksist bir tarihçi olan Hobsbawm, Fransız İhtilali sırasında yüceltilen millet ve milliyetçiliğin hem siyasi hem de iktisadi anlamda ilerlemeyle bağlantılı olduğunu ifade ederek milliyetçiliğin birleştirici bir güç olarak açığa çıkabileceğini ima etmektedir.

Materyalist modernistlerin aksine milliyetçiliğin materyalist olmayan yönlerine yapmış oldukları analizlerle dikkat çeken Ernest Renan ve Benedict Anderson'un çalışmaları, kültürel modernistlerolarak ifade edilmelerine yol açmıştır. Renan, milliyetçiliğin kültürel ve toplumsal boyutlarına dikkat çektiği "What is Nation?" (Ulus Nedir?) isimli konuşmasında, milliyetçiliğin özcü yorumlarına karşı çıkarak ortak dil, din veya ortak toprak inancının bir ulusu tanımlamakta yetersiz kalacağını savunmuştur. Renan (2016, s. 8), ulusun "bir ruh, tinsel ilke" ve tarihin derin karmaşıklıklarının ürünü olduğunu ileri sürmüştür. Bundan dolayı ulusların yaratılmasında milliyetçi söylem aracılığıyla geçmişi kolektif unutma eğilimi yaratmanın önemliolduğuna yönelik vurgusuyla dikkat çeker. Renan, uluslarıbasitçe durağan varlıklar olmaktan ziyade insan ihtiyaçlarını yaratıları olarak görmenin yolunu açmıştır. Anderson (2000) ise Renan'ın dikkat çektiği bu konuya ayrıntılı olarak değinerek özellikle kapitalist yayıncılığın yeni biçimlerde hayal edildiğini, soyut toplulukların inşa edilerek milliyetçiliğin doğuşunu destekleyecek temellerin atıldığını ifade etmiştir. Anderson'un bu yorumu, milletin "hayalî cemaat” olduğu fikrini yaygınlaştırmıştır. Bilindiği gibi Anderson (2000, s. 6), milletin hayalî olduğunu çünkü en küçük milletin mensuplarının bile diğer mensuplarının büyük 
çoğunluğunu tanımadığını yine de herkesin zihninde içinde bulunduğu cemaate dair bir imge olduğunu öne sürmüştür. Anderson, Roma Katolik Kilisesi'nin hegemonyasının çöktüğü reform dönemine bununla bağlantılı olarak Latincenin düşüşe geçişine ve kapitalist yayıncılığın gelişmesiyle birlikte yerel dillerin ortaya çıkışına dönerek milliyetçiliğin izini sürmüştür. Anderson, milliyetçi fikirlerin 18. yüzyıl sonlarında ve 19. yüzyıl başlarında Amerika'da, 1848 yılından sonra ise Avrupa'da basılı bir şekilde yayılmasıyla çok yakından ilgilenen bir dizi aktör tespit etmiştir. Amerika'daki aktörlerin büyük bir kısmı Criololar oluşturduğunu, Avrupa hanedanlık rejimlerinin de bu süreçte önemli rol üstlendiğini belirtmiştir. Anderson'un kuramı esasında milliyetçiliği, modernleşmenin etkisiyle yalnızca bir yaratı ve dolayısıyla gerçek olmayan bir şey olarak görmeyi reddeder. Anderson'a göre uluslar ve milliyetçilik tam da hayal edildiklerinde gerçek olurlar. Materyalistleri kültürel modernistlerden ayıran en önemli özelliğin bu olduğu ifade edilebilir. Modernist ve neomarksist olan diğer bir düşünür Tom Nairn'in ifadelerine de bu bağlamda özellikle yer vermek gerekmektedir. Nairn açıkça modernist bir çerçevede hareket ederek Marksist düşünürlerden faydalanarak milliyetçiliği, küresel ölçekte merkezî ve çevresel ülkelerde meydana getiren kapitalist dünya düzeninin neden olduğu eşitsiz gelişmeye bir tepki olarak tanımlamıştır. Ona göre milliyetçiliğin 'asıl kökleri'ne halk tane de bireyin bir çeşit bütünlük ve kimlik arayan bastırılmış tutkularında yatmaktadır, milliyetçiliğin kökleri dünyadaki 'siyasal iktisat' düzeneğinde yatmaktadır (Nairn, 2015, s. 77). Genel olarak bakıldığında kültürel modernistlerin görüşlerinin etkisi, İngiltere'nin ve Fransa'nın ulus kavramına yönelik tanımlamalarında görülmektedir. Kültürel modernistlerin ifade etmiş oldukları gibi ulus,bir siyasal topluluk olarak görülerek vatandaşlık bağlarının ve bağlılıklarının önemi vurgulanmıştır. 1789 Fransız Devrimi'yle Rousseau'nun 'halk egemenliğine' yönelik vurgusuyla birlikte temellendirilmektedir (Heywood, 2006, ss. 154-156). 


\section{Tablo 1}

Metodolojik Milliyetçiliğin Temel Dayanak Noktaları (Akyiğit, 2017, s. 52).

\begin{tabular}{|c|c|c|c|c|c|}
\hline & & Ulusal Kimlik & $\begin{array}{l}\text { Ulusun } \\
\text { Unsurlary } \\
\text { Ōnemli Olan } \\
\text { Mitler } \\
\end{array}$ & Uygulanan temel politilkalar & $\begin{array}{l}\text { Sonuç } \\
\text { a)Toplum yapisı } \\
\text { b)Altör tutumları }\end{array}$ \\
\hline 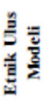 & $\begin{array}{l}\text { Alman } \\
\text { Modeli }\end{array}$ & $\begin{array}{l}\text { Tarihsel } \\
\text { doğal etmikliğe yami soya } \\
\text { bağlı }\end{array}$ & $\begin{array}{l}\text { Hukukun yerine } \\
\text { geçen yerli kültür, } \\
\text { din ve adetlerdir. }\end{array}$ & $\begin{array}{l}\text { Tecrit politikalan, zorunlu gö́, nüfus } \\
\text { muibadeleri, Etwik temizlil. }\end{array}$ & $\begin{array}{l}\text { a) "Biz", "ōteki" ayrum, çatışma ortamu, kültürel } \\
\text { farkhlığı kabullenmeme } \\
\text { b)Etnik/rrkç milliyetçilik, Travma, aynlma, özerklik } \\
\text { isteme, ulusal kimliği benimsememe, }\end{array}$ \\
\hline \multirow{2}{*}{ 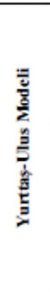 } & $\begin{array}{l}\text { Fransiz } \\
\text { Modeli }\end{array}$ & $\begin{array}{l}\text { Ust kimlik olarak kabul } \\
\text { edilerek, kültürel } \\
\text { türdeşlik, } \\
\text {-Yasal eşitlik ortak vatan } \\
\text { anlayıg̨ } \\
\end{array}$ & $\begin{array}{l}\text { Anayasaya bağlı } \\
\text { yurttạ̧lı algısı, } \\
\text { Ortak Vatan } \\
\text { Kader anlayı̨̣1, }\end{array}$ & 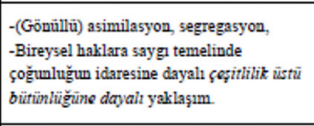 & $\begin{array}{l}\text { a) Kültürel tuirdeşlik, ulusal bürünleşme ve uyum } \\
\text { ortam, türdeş toplum, vatanseverliğe bağh geliggen } \\
\text { "yurttaşlik" "kardeşlik", algısı } \\
\text { b) Sivil milliyetçilik, kültuirel ulusal kimliǧe devlete } \\
\text { yönelik "aidiyet", "Sadakat" }\end{array}$ \\
\hline & $\begin{array}{l}\text { Anglo } \\
\text { Sakson } \\
\text { Modeli }\end{array}$ & $\begin{array}{l}\text { Üst kimlik olarak kabul } \\
\text { edilerek, külrürel } \\
\text { çeşitilìğin korunması, } \\
\text {-Yasal eşitlik } \\
\text {-Ortak vatan anlayışı }\end{array}$ & $\begin{array}{l}\text { Anayasaya bağlı } \\
\text { yurttą̧llk algısı, } \\
\text { Ortak Vatan } \\
\text { Kader anlayı̧̣ı }\end{array}$ & 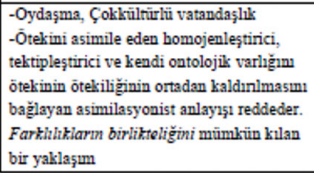 & $\begin{array}{l}\text { a) Kültürel çeşitliliğin korunması ve kabulï, ulusal } \\
\text { bütünleģme ve uyum ortam, vatanseverliğe bağhl } \\
\text { gelişen siyasal "aidiyet" "sadakat" } \\
\text { b) Sivil, kültürel milliyetçilik, ulusal kimliğe devlete } \\
\text { yönelik "aidiyet", "Sadakat" }\end{array}$ \\
\hline
\end{tabular}

Sonuç itibarıyla ulus devletlerin tarihi, ulusların kültürel özellikleri Tablo 1'de gösterilmeye çalışıldığı üzere temelde ilkçi ve modernist kuramın temellendirilmesiyle ele alınarak idealleştirilmektedir. "Kavrama ilişkin kuramsal tartışmalarda Fransız düşünürler ve Alman düşünürler karşı karşıya gelerek” (Koyuncu, 2018, s. 22 )milliyetçiliğin iki uç odak noktada açıklanması yaygın bir ön kabul olarak görüldü. "Fransız düşünürler ulusu, bireysel bağlllıkların kabul edilmesinden hareket eden evrensel bir oluşum olarak tanımlarken Alman düşünürler ulusu, ortak bir dil hatta etnik gruba doğrudan ait olmaya dayalı bir cemaat vurgusu yapıyorlardı" (Jaffrelot, 1998 akt. Koyuncu, 2018, s. 22). Bununla bağlantılı olarak yurttaş ulus modeli (sivil) ve etnik ulus modeli bağlamında -Hans Kohn'un (1929) önerdiği şekliyle- milliyetçilik konusu tartışılmıştır. Bu idealleştirme, 19. yüzyılda ortaya çıkan milliyetçilik biçimlerini ve tartışmalarını esas alan bir temele dayanmaktadır. Örneğin; yurttaş ulus modeli bağlamında modern doğal hukuk kapsamında tanımlanan ulusal kimlik, toplumu yapay bir oluşum olarak düşünen, bireyselci sözleşme felsefesine dayanan bir anlayışı kendi içerisinde barındırmaktadır. Burada açık bir şekilde ulus, bütün olarak tanımlanarak düzenlenmektedir. Öte yandan kendisini kültürel bir bağ üzerinden tanımlayan halklar, tarihsel varlıklara gönderme yaparak dil, din ve soy gibi ögeleri öne çıkartarak etnik temelli bir ulusal kimlik tanımlayabilmektedirler. Buna göre Doğu'da görülen milliyetçilik etnik temelli iken Batı da görülen milliyetçilik sivil niteliktedir (Kohn, 1929; Özkırımlı, 2013). Bu tür idealleştirmeler, "metodolojik milliyetçilik” anlayışını da beraberinde getirmiştir. Bu yaklaşım, geçmişi etnik veya vatandaşlık bağlamın- 
da genelleştirerek kavramsal, soyut bir bağlamda kutsayarak alma eğilimindedir. ${ }^{6}$ Dolayısıyla milliyetçiliğin özgünlüğü, bireysel kimliğin kaynağını, hâkimiyetin taşıyıcısı, sadakatin merkezî öznesi ve kolektif dayanışmanın temeli olarak görülen bir halk topluluğuna yerleştirmesinden gelmektedir. Halk; sınırları ve doğası çeşitli biçimlerde tanımlanan bir somut cemaatten daha büyük, homojen ve statü, sınıf, coğrafi bölge hatta bazı durumlarda etnik köken çizgileri boyunca yapay olarak bölünebilen bir şey olarak görülmektedir (Greenfeeld, 2017, s. 20). Bu yapay oluşum Gellner'in (1992, s. 56) “ulusçuluk, göründüğü şey değildir ve her şeyden önemlisi kendisine göründüğü şey değildir... Ulusçuluk tarafından kullanılan kültürel dilimler ve yamalar genelde keyfi tarihsel icattır..." ifadelerinde açıkça görülmektedir. Gellner (1992), milliyetçilik öncesi çağda yani imparatorluklar çağında, kültürel heterojenliğin bir kural olduğuna değinir. Bu açıdan bireylerin kimlik referanslarının, dinlerinin, toplumsal statülerinin ya da yerel bir cemaate aidiyetleri bağlamında geliştiğini belirtir. Ulusal kimliklerin şekillenmesi ise bu referansların alt üst edilerek, uyuşmazlığın egemen olduğu yerde birliğin sağlanarak, sınırların kimliklerin üst üste yığıldığı veya süreklilik arz eden mekânlara göre çizildiğini vurgular. Dolayısıyla ulus, her biri devlet tarafından korunan, derinden içselleştirilmiş eğitime bağımlı yüksek kültürlere dayanan, sınırları dil tarafından belirlenmiş yeni bir toplumsal örgütlenmenin sonucudur (Anderson, 2000; Gellner, 1992). Hobsbawm (2006, s. 2) ise uluslaşma sürecini bir proje olarak betimleyerek geleneğin icat edilmesi aracılığılla bu sürecin gerçekleştiğini ifade etmiştir. Ona göre "icat edilmiş gelenek deyimi, gerçekten icat edilmiş, inşa edilmiş ve formel düzlemde kurumsallaşmış gelenekleri olduğu kadar kolayca izi sürülemeyecek şekilde kısa ve belirlenebilir zaman diliminde ortaya çıkmış olan ve hızla yayılan gelenekleri kapsar" (Hobsbawm, 2006, s. 2). Bu tanımlamalar üzerine -özellikle Hobsbawm'ın ifadelerinden yola çıkarak- Smith (1996, s. 188) uluslaşma sürecinde neden bazı icat edilen geleneklerin işlevsel olduğunu bazılarının olmadığını; neden geçmişle bağları koparmak üzere yeni bir tarihsellik yaratıldığını; siyasi birlik ve ulusal bütünlük kurma çabalarının neden bazı toplumlarda karşılık bulurken bazılarında bulamadığını sorgulamıştır. Bununla ilişkili olarak Hobsbawm gibi modernistlerin milliyetçilik gibi karmaşık bir fenomeni tek bir faktörle açıklayarak ve tarihsel gerçekliğin çok yönlü yapısını göz ardı ederek indirgemeci bir yaklaşım ortaya koymakla eleştirildiği (Özkırımlı, 2013, s. 150) ifade edilmektedir. $\mathrm{Bu}$ eleştirilerden yola çıkarak yapay tanımlamaların ötesinde "insan topluluğunu 
düşünmek istiyorsak onu siyasallık açısından yani topluluğun kendini düzenlenmesini ve tanımlamasını belirleyen merkezî unsur açısından ele almamız gerekir" (Gauchet, 2013, s. 35). Ancak modern ulus tüm bu siyasallığın ötesinde yegâneform olarak belirmektedir. Oysaki milliyetçilik bağlamında gelişen ulus tanımlamalarının gerçekliği bu bağlamda açığa çıkabilecek aktör tutumları çift yönlüdür: "Hem kendini mutlaklaştırma eğiliminde olan bir tikelciliğin egemenliğindedir hem de az çok yozlaşmış bir evrenselcilikten yana gözükür ve çoğunlukla da bu ikisi arasında gerilim etrafında şekillenir. Etnomilliyetçilik veya vatandaşların ortaklığı olarak tasarlanabilir; iki durum için yapılan analiz, ne aynı mantığı ne aynı tarihsel olaylar dizisinde aynı toplumsal failleri takip eder" (Zawadzki, 2018, s. 210). Tüm bunların yanı sıra "metodolojik milliyetçiliğin teamülleri; bireyi, devleti ve milleti etkileyen biçimlendirici ve bağlamsal faktörleri inkâr ederek eşi benzeri olmayan bir şey olarak tanıtırlar" (Halliday, 2015, s. 359). Ayrıca "Avrupa merkezcilik bağlamında okunan ulus devlet eklemlenmesinin Avrupa'da izlediği yolu ya Avrupa dehasina özgü bir model olarak sunmak ya da gecikmeyle de olsa sonunda başka yerlerde de kendini kabul ettirecek bir yasa olarak görmektir" (Amin, 2007, s. 232). O halde "metodolojik milliyetçilik" terimi sadece çok spesifik kültürel, sosyotarihsel ve siyasi konfigürasyonları belirlememekte, bazı belli spesifik zaman ve mekân kavramlarına da işaret etmektedir. Örneğin; Aydın (2000), ulus, milliyetçilik ve ulus devletin temelde dört farklı biçimde göründüğünü ifade ederek bir tasnifte bulunmuştur (akt. Koyuncu, 2018, ss. 36-37). İlk olarak İngiltere ve Fransa'da kapitalizmin doğuşuna ve dünya ekonomisinin biçimlenmesine paralel olarak milliyetçiliğin ulusal ekonomiyi yaratmak gayesiyle ortaya çıktığı ifade edilir. İkinci olarak Almanya, İtalya ve Çekoslovakya'da uluslaşmayla birlikte kültürel milliyetçilik ekseninde gelişen ulus devletleşme sürecinin kendisini gösterdiği; üçüncü olarak Balkanlar, Orta Doğu, Güney Amerika, Afrika ve Asya ülkelerinde ise milliyetçiliğin aydınlar, küçük burjuvazi ve sömürgecilik ekseninde gelişerek ulus devletleşmenin kendisini gösterdiği uluslaşma sürecinin ise en son gerçekleştiği belirtilmektedir. Dördüncü kategoride aydınlar, küçük burjuvazi ve yabanc1 işgalinin temel dinamikleri oluşturduğu ve Doğu Avrupa, bazı Balkan ülkeleri, Portekiz ve İspanya'da milliyetçilik ekseninde gelişen uluslaşma ve ulus devlet biçiminde görülen bir süreçten bahsedilmektedir.

Genel itibarıyla milliyetçiliğin bu tarz belli tasnifler bağlamında değerlendirilmeye tabi tutulması birçok açıdan eleştirilmektedir. Bu eleştirilerin ortak noktası, bazı ulusların aslında anlamlı bir biçimde protomilliyetçi, etnik, etnosembolik, kültürel veya premodern ulusal, kimlik ve kültür gibi çeşitli biçimlerde tanımlanan özellikleri taşır yönde anlaşılabilmesi ihtimali gibi sorgulama yollarını sınırlandır- 
ma biçiminden rahatsız olmalarıdır. Örneğin; Smith'e (2017, ss. 30-32) göre ilkçi/ modern yaklaşıma bağlı ele alınan millet ve milliyetçilik açıklamalarında gözden kaçırılan nokta, milletlerin hem kendi içlerindeki hem de kendi aralarındaki çatışmaların toplumsal ve sembolik etkisidir. Bu açıdan karmaşık millet oluşturma süreçleri, ideolojileri ve kolektif eylemleri güdüleyen öznel ve sembolik kaynakların anlamları görmezden gelinmektedir. Daha da önemlisi 18. yüzyıldan önceki hiçbir unsurun önem arz etmemesine, söz konusu dönemlerin keyfî biçimde sınırlandırılmasına neden olmaktadır. Ayrıca metodolojik milliyetçiliği besleyen kuramların temelinde var olan "ulusal tecrit ve norm gibi iç kaynaklı kararlılık varsayımı yanlış yönlendiricidir" (Halliday, 2015, s. 359). Buradan hareketle milliyetçiliğin günümüzün kaygılarına uygun olarak eski gelenekleri ve kimlikleri seçtiğine, yeniden biçimlendirdiğine ve kimi zaman yeniden yarattığına inanılmaktadır. Bazı durumlarda milliyetçilerin seçimleri, bilinçli olarak ortaya konulan bir siyasi tasavvurun ürünü olmayıp çeşitli olasılıkların hatta tesadüflerin sonucu olabilmektedir. Bundan dolayı 18. ve 19. yüzyılda açığa çıkan milliyetçilikleri bütün milliyetçiliklerin temeline oturtmak hatadır. Nitekim milliyetçilikler de farklı dönemlerde farklı bağlamlarda kendisini gösterebilmektedir. Dolayısıyla birbirlerinden bağımsız kültürel pratiklerden oluşan toplulukların uyumlu bir "etnik" kültür oluşturacak şekilde kaynaştırılması içinde önceden planlanmış bir müdahale şart değildir. Halk kültürünün farklı yansımalarını ya da millî ruhu keşfetme isteği çoğunlukla önceden düşünülmüş, tasarlanmış milliyetçiliğin ürünü değildir (Özkırımlı ve Sofos-Spyros, 2013, s. 9). Burada mesele, nötr coğrafi ya da kartografik pozisyonlar değildir aksine mekânsal metaforlar, tarihine yayılmış bir miras ve kendi içindeki mekân ve zaman algısına kadar uzanan daha geniş bir zaman semantik sahaya açılmaktadır. Bu değerlendirmeler bizi 'etnosembolist' (Smith, 2017) yaklaşıma götürmektedir. Çünkü etnosembolizm diğer yaklaşımların aksine milletlerle ve milliyetçilikle ilgili genel bir kuram oluşturmayı amaçlamamaktadır. Millet ve milliyetçilikle ilgili konuların temelini oluşturan cemaat, bağlilık, sembolizm ve ayin gibi konuların sosyotarihsel analizini yaparak toplumsal ve kültürel tarihi temsil edebilecek kavramlar ve sezgisel araçlar sunmayı amaçlamaktadır. Diğerlerinin çoğu zaman ihmal ettiği etnik geleneklerin tarihini ve içeriğini özellikle vurgulamaktadır. Etnosembolist yaklaşım, ulusların çoğunun zaman içerisinde bunun çok ötesine geçseler de önceden var olan etnik bağ ve hissiyatlar temeli üzerinde inşa edildiğini vurgulamaktadır.Aynı zamanda ulusların milliyetçilikte harekete geçirmek istedikleri ve belirlenmiş halkın çoğunluğunda en çok yankı bulacak etnik sembolleri, anıları ister istemez kullandıklarının altını çizmektedir.Dolayısıyla milliyetçiliğin çeşitliliği kadar tekliği de önemlidir. Tekliği, bütünleşik bir alanda 
sembolik ve toplumsal boyutlarla ilgili genellemeler yapılmasına imkân verir. Çeşitliliği ise milliyetçi hareketler alanına kıyaslamalar ve karşılaştırmalar getirerek belirli milliyetçiliklere özel sembol, değer, gelenek, mit ve ritüellerin incelenmesini desteklemektedir. Böylelikle etnosembolik analiz, siyasi arkeoloji, özgün tarihsel milliyet, seküler din gibi kavramlara dikkatimizi çekerek millet ve milliyetçiliğin öznel ve müessir boyutlarına dikkatimizi yöneltir (Smith, 2017, s. 113).

Smith'in dikkat çektiği bağlamlardan yola çıkarak metodolojik milliyetçiliğin kendi içerisinde barındırmış olduğu boşlukları aşabilmek belki de Hassner'in (2018, s. 264) vurguladığı şu soruya karşılık verebilmekten geçmektedir: "Ayrı ayrı ele alındıklarında basitçe ideal tipler olan farklı türden milliyetçilikler söz konusu iken aslında bunlar gerçekte var olmuş, bütün milliyetçiliklerde değişik oranlarda bulabileceğimiz farklı boyutları mı temsil ediyor ya da doğudan batıya, kuzeyden güneye geçilirken milliyetçilik yapısal değişiklikler mi gösteriyor yoksa neredeyse bütün milliyetçilikler, bir ömrün farklı dönemlerine veya gelişimin farklı merhalelerine benzer şekilde hep aynı aşamalardan mı geçiyor?"

\section{Konstrüktivist Bir Dönüș: \\ Ulusa, Evrensel ve Tarihsel Dönemlerin Ötesinde Bakmak}

Metodolojik milliyetçiliğin ilk açmazları arasında Batılı ulustan kültürün yerelliğini gözlerden uzak ve yaygın biçimde yaşamayı temsil eden bir bakış açısıyla kendisini gösteren evrenselleştirme ideali, tarihsel dönemlere bağlı olarak genelleştirilen yaygın ulusçuluğun etkileri yer almaktadır. Bundan dolayı milliyetçilik, Tablo 1'de gösterilmeye çalışıldığı gibi meşru metodolojik ilkelere bağlı okunurken bazı sorular asla sorulmamıştır bazı olasılıklar üzerinde düşünülmemiştir. Bu noktada "eleştirel kuram ve postmodernizm anlayışından beslenen konstrüktivizm, toplumsal bir milliyetçilik ve ulus çözümlemesini geliştirmeye çalışmaktadır. Bu kuramda esasen ulusu oluşturan aktörler ve eylem doğası gereği toplumsal, geleneksel olarak temellendirilmiş kimliklerin ürünü olarak ele alınmaktadır" (Reus-Smith, 2015, ss. 190-191). Dolayısıyla aktörlerin kendi öznel tarihlerinden beslenen kültürel örüntüler aracılığılla milliyetçilik, bireysel ve insan faaliyetlerini şekillendirdiği ölçüde önemli görülmektedir. Dolayısıyla konstrüktivist bakış ile etnik ve kültürel ya da liberal, sivil veya muhafazakâr milliyetçilik tartışmaları zemininde ilerleyen "metodolojik milliyetçiliğin" benimsediği "ontolojik” kabullerin aşılması öngörülmektedir. Başka bir ifadeyle "diskursif hitabın” ötesinde ulusların özelde hangi türden "kimlik, kültürel örüntüler/özellikler" üzerinden anlam kazandığı konusu açığa çıkartılmak istenmek- 
tedir. Çünkü Karakaş'ın (2007, s. 74) da ifade ettiği gibi Batı dışı toplumlardaki ulusçuluk anlayışı, doğuşu, gelişimi ve işlevleri açısından Batı Avrupa'da ortaya çıkan ulusçuluk anlayışından farklıdır. Buna rağmen ulus olgusu bir düşünce kodu; ulus devlet ve ulusçuluk olguları da siyasal bilinç kodu olarak farklı olsa da Batı dışı toplumlarda üçüncü dünyada etkisini hissettirerek yeni bir hareketliliğin ve tavrın oluşmasını sağlamıştır.

Konstrüktivist duyarlılık, metodolojik milliyetçiliğin dayandığı bu temel görünmez konuları aşabilmek için "analiz birim ve düzeylerini ya da aktörler ve onların içinde yer aldığı yapıların seçilmesi” (Wendt, 2016, s. 22) gerektiğine yönelik bilgi sunmaktadır. "Konstrüktivistlere göre evrensel rasyonel aktör bir efsanedir. Tarihsel kültürel olarak muhtemel inanışlar, aktörlerin kendilerini nasıl anladıklarını belirler ve olduklarını düşündükleri şey sadece kendi çıkarları değil ayrıca bu çıkarları farkına varma yöntemlerini etkiler" (Reus-Smith, 2015, s. 194). Böyle bir yaklaşım biraz önce ifade edilen "metodolojik milliyetçiliğin" benimsediği "ontolojik” kabullerin anlatısından daha faydalı bir anlayış ortaya koymaktadır. Bu yaklaşım,ulus ve ulusçuluğun doğasına özellikle farklı kurumsal, kültürel özelliklere yönelik farklı bir açılım sunmaktadır. Dolayısıyla ulus devletlerin normatif yapısına bunun devletin toplumsal kimliğini nasıl etkilediğine değil ulusun kültürel örüntülerinin hangi bağlamlarda oluştuğuna bakılması sağlanabilecektir. Bu kuramsal bakış açısı özünde ulusu oluşturan aktörlerin kendi içlerinde barındırdığı ahlaki değerlerini, inançlarını sorgulamayı amaçlamaktadır. Ulusla birlikte tasavvur edilen ulusal kimlikle bütünleştirilen kültürel kimliğin muktedir sembolik ve etkileyici kaynakları olan bu siyasi oluşumların yazıtındaki türdeşlik üzerine olan vurgunun amacı; kültürel bir güç olarak ulus hakkındaki tartışmalara hâkim olan tarihselciliğin ötesine geçmeye hizmet edebilmektir. Bu tür bir bakış açısı, daha açık bir şekilde açıklanmak istenirse iki şekilde ayrıntılandırılabilir: İlk olarak sabit bir kimlik okumasıyla gelişen milliyetçilik çözümlemeleri beklenilen aksine sosyokültürel temelleri açı̆̆a çıkarmamaktadır. Çünkü araştırmanın "özne” ve "nesnesi” arasında aşılamaz uzaklık söz konusudur. Konstrüktivist duyarlılık,mekânların heterojenliğini, zamanın bölgesel ontolojilerini ve farklı uygulamaları, anlatıları, kültürel örüntüleri, toplumsal anlamların görülmesine imkân sağlamaktadır. İkinci olarak milliyetçiliğin yapılandırılması gibi sorunlara ve aynı zamanda güçlü kimliklere hitap edebilecektir. Böylelikle inşa edici bir faktör olarak milliyetçilik çözümlemelerinden kaçınıldığı zaman iç ve dış boyutların sınırları ve verimsiz etnik-sivil milliyetçilikler bağlamında ilerleyen ikilikler aşılabilecektir. Farklı tarihsel zamanları ve mekânları bir tek despot dünya zamanına sı̆gdırmaya çalışmaktan vazgeçebilecektir. 
Milliyetçilik kuramları genel olarak iki ana kategoriye bağlı olarak okunmaktadır: Milliyetçiliği, kimliklerin şekillendirmesine dayanan modernleşmenin bir ürünü olarak gören kuramlar ve milliyetçiliği, mevcut etnik özelliklerin sürekliliği olarak yorumlayan kuramlar. Fikirlerin ve ulusal tahayyülün şekillenmesini tasvir eden bu milliyetçilik kuramları, ideolojinin doğuşunu kavramaya elverişli olsa da milliyetçilik serüveninin sonraki etaplarını analiz etmek için başka yaklaşımlara başvurmak gerekmektedir (Jaffrelot, 2018, s. 80). Calhoun'un (1997, s. 123) tespitiyle "milliyetçilik, tek bir kuramın bütünüyle açıklanamayacağı kadar aşırı bir çeşitlilik ihtiva ediyor. Muhtelif milliyetçiliklerin özgül eğilimleri ve kapsamları büyük ölçüde, özgül tarihsel gelenekler, lider yaratıcılığı ve uluslararası bağlamın olumsallığı tarafından belirlenir.” Bu bakış açısı bizi metodolojik milliyetçiliğin açmazlarına tekrar götürür ve bize Hall'un (1993) milliyetçiliğe yönelik tek ve evrensel bir kuram ve kavramsal çerçeve olamayacağına yönelik vurgusunu hatırlatır. Dolayısıyla konstrüktivist duyarlılığa sahip kuramcıların (Baumann, 1999; Barth, 2001; Habermas, 2002), kimliğin tarihsel süreçte gelişen ve değişime uğrayabilen, diyalektik ve diyalojik etkileşimin sonucunda geliştiğine yönelik yorumlamalarından hareketle metodolojik milliyetçiliğin eylem ve kültür odaklı çözümlemesini dikkatle irdelenmesi gerektiğini hatırlatır. Bu noktada çalışmada üzerinde durulmak istenilen konu, metodolojik milliyetçilik çözümlemelerinde göz ardı edilen kültürün yaratacağı nedensel farklılıklara dikkat çekerek ulusal aktörlerin içkin özne olma biçimlerinin ilişkisel boyutunu açıklığa kavuşturmaktır. ${ }^{7} \mathrm{Bu}$ ilişkisel boyut, metodolojik milliyetçiliğin kendi içinde barındırdığı tarihsellik ve mekân sorununu aşmaya yön tutacaktır. ${ }^{8}$ Çünkü "ulus devlet, modern toplumun temel siyasi biçimi olarak bir kez yerleştiğinde sanki şeyler daha fazla değiştikçe güçleri daha fazla aynı kalırmış ve hiçbir şey gerçekte veya kökten değişmiyormuş gibi görünür"9 (Fine ve Chernilo, 2017, s. 392).

7 Yapı eylem ikililiğinin ilişkisel boyutu son zamanlarda kültürel psikolojiden bilişsel antropolojiye, bilişsel sosyolojiden postyapısalcılığa, Wittgensteincı sosyal psikolojiden sembolik etkileşimciliğe, yapılanma teorisinden etnometodolojiye kadar çeşitli sosyal bilimsel geleneğin ana önermesi olarak tartışılmaktadır. Bu çalışmada söz konusu olan teorik açılımlara ayrı ayrı yer vermek yerine metodolojik milliyetçiliğin, kültürü tanımlama ve bu bağlamda yapı-eylem ikiliğindeki ilişkisel boyutun nasıl göz ardı ettiği gösterilecektir.

8 Bu bağlamda çalışmada dikkat çekilmek istenilen konu, Hall'un (2017) tarihin biricikliği karşısında anlam analizini teorileştirmeden soyutlayan yapısalcı/tarihselci ayrışmasıyla karşıtlık içinde, teorik kavramlara kültürel içeriği dâhil etmek ve gerçekte kavramların inşasını bu ilke üzerinde temellendirmenin mümkün olacağına yönelik saptamasıyla eş değerdedir. Hall özellikle Max Weber'in 'ideal tipler' olarak adlandırdığı kavramsallaştırmasından esinlenerek yapısalcıların aksine anlamı kendi özel tarihsel özellikleri içinde incelenebileceğini, kültürel anlamları teorileştirilen bir tipten veya ikili karşıtlıklardan sapan daha zengin daha kompleks bütünlükler olarak ele alınabileceğini hatırlatır. 
Metodolojik milliyetçiliğin tarihsellik ve mekân algısı sorunu özellikle milliyetçiliği kültürel egemenliğe karşı bir cevap olarak analiz edenler ve onu bir entelektüel nüfuz olgusu olarak okuyanlar arasında da kendisini göstermektedir. Bu iki yaklaşımın ana noktası, milliyetçiliğin yayılımını ve etkisini tarihsel failler aracılığıla merkezî bir zaman diliminden ve tarihsel failler sıfatıyla okumasına dayanmaktadır (Dahbour ve Ishay, 1995). Metodolojik milliyetçilik hatalı bir şekilde dış dünyanın etkisi altında kalan bütün toplumların benzer ölçülerden ve süreçlerden geçerek milliyetçiliği özümsediğini ve ulus devlet olduklarını varsayan bir ön kabul sunmaktadır. Örneğin; Kohn (1929; 1995), bireyin özgürlüğü ve ulusal örgütlenme ile ilgili İngiliz kökenli fikirlerin, Fransız düşünürler tarafından diğer ülkelere yayıldığını ve 18. yüzyılın ortak şuuruna yerleşecek şekilde benimsendiğini belirtmiştir. Akabinde Asya'nın, Fransız düşünürler tarafından yaygınlaştırılan milliyetçilik idealinde kendisini yeniden keşfederek dönüştürdüğünü ifade etmiştir. "Hâlbuki Fransa tecrübesi, Fransa sınırlarından dişarı çıktığı andan itibaren boyutları ciddi bir şekilde değişiklik geçirmiştir. İşin ilginç tarafı, ulus inşasına ilişkin Fransa tecrübesinin tekilliğidir. Spivak'ın Faoucault'ya atıfla epistemik şiddet diye adlandırdığı durum, milliyetçilik çalışmalarında özellikle modernist perspektifte verilidir" (Buçukcu, 2020, s.192). Hayes (1960, s. 176), milliyetçiliğin Asya ve Afrikalı halklar üzerindeki etkisini "tarihsel bir doğaüstü dinin canlandırıcısı" olarak tanımlamaktadır. Oysaki "bu yayılmacı anlayış, ulus devletlerin neden başka bir Avrupa ideolojisini değil de milliyetçiliği taklit ettiğini açıklayamadığı gibi bu tercihin bilinçli olup olmadığını veya bu tür bir yabancı etkinin siyasal bir cemaate duyulan sadakati nasıl yıktığını ve yeniden kurduğunu da açıllamaz" (Jaffrelot, 2018, s. 50). Rasyonel ve genelgeçer akıl yürütmelerin aksine milliyetçiliğin bölgesel olarak yerleşik zengin olan yerli kültürünün dönüşüm geçirerek nasıl belirginleştiği üzerinde durulmalıdır. Batı tarzı standartlaşma ve milliyetçilik görünümleri yaygınlaştırma arzusu beraberinde Nandy'nin $(1987 ; 1994)$ vurguladığı gibi toplumsal dönüşümlerin kültürel bağlamlarını vurgulamanın önemini de unutturmuştur. ${ }^{10}$ Böylelikle dünyanın her yerinde Batı tarzı milliyetçilik ve ulus devlet modeli, Batı dışı kültürlere hiç ayrım yapmaksızın empoze edilmiştir. Bu sürecin uluslaşma dinamiklerinin üçüncü dünya toplumlarının temel dinamiklerine yabancı olduğunun altını çizen Aydın 
(2000, s. 78), dünya ekonomik sisteminin ülkeleri ve toplumları birbirine yaklaştırıcı, onları her bakımdan tek biçimli kılıcı etkisi, toplumları tek bir ulus devlet çerçevesi içine soktuğunu, dinamiklerin farklılığı bu biçim içine sıkıştırılmış toplumlarda bir kimlik bunalımına yol açtığını ifade etmiştir. Aynı zamanda bütün Asya, Afrika ve Güney Amerika neredeyse sınıları cetvelle belirlenmiş yapay sınırların, sorunları körükleyici cenderesi içinde kalmasına neden olduğunun özellikle “Orta Doğu'da ulus kimlik kavramı, var olan mozaik yapı ile tam bir çelişme ve çekişme içinde olduğundan" (Harik, 1972 akt. Aydın, 2000, s. 79) bugünkü sorun alanlarının da geçmişten gelen çözümsüzlükleri sürdürdüğünün altını çizmektedir. Hobson (2015), sosyal bilimlerde yaygın olan bu anlayışı yani ulus devletlerin içerisinde barındırdığı dinamik akışkan süreçleri, özsel farklılıkları ve çoğullukların göz ardı edilmesini sadece ana odaklanarak içinde bulunan sürecin açılkanabileceği anlayışın yaygınlık kazanmasını "kronofetişizm"; tüm sistemlerin benzeşik veya eşbiçimli olarak (örneğin; aynı yapıya sahip olmak gibi) okunmasını "temposentrizm" olarak tanımlamaktadır. Tarihsel sosyolojinin temel argümanları bağlamında gelişen bu bakış açısı ve bu sürecin ardılları buna bağlı gelişen yanılsamalar, Tablo 2'de özetlenmektedir. 
Tablo 2

Tarih Dışılı̆̆ın İki Baskın Biçiminin Kavramsallaştırılması (Hobson, 2015, s. 19)

\begin{tabular}{|c|c|}
\hline Tarih Dışılık Biçimi & Sonuçta Oluşan Yanılsamalar (Tehlike) \\
\hline \multirow{4}{*}{ Kronofetişizm } & $\begin{array}{l}\text { Üç yanılsamaya sebep olan bir } \\
\text { tarihdışılık biçimi }\end{array}$ \\
\hline & $\begin{array}{l}\text { 1) Somutlaştırma yanılsaması: } \\
\text { Şimdiki zamanın geçmişten etkin } \\
\text { bir şekilde soyutlandığıböylece } \\
\text { tarihsel sosyozamansal bağlamını } \\
\text { belirsizleştirdiği ve statik, kendi kendini } \\
\text { oluşturan, özerk ve somutlaştırılmış bir } \\
\text { varlık olarak gösterildiği yanılsama. }\end{array}$ \\
\hline & $\begin{array}{l}\text { 2) Yerlileştirme yanılsaması: } \\
\text { Şimdiki zamanı oluşturan toplumsal } \\
\text { gücün, kimliksel/toplumsal } \\
\text { dışlanmışlığın ve normların tarihsel } \\
\text { süreçlerini izleyerek şimdiki zamanın } \\
\text { doğal insan zorunlulukları gereğince } \\
\text { 'kendiliğinden' ortaya çıktığı temeline } \\
\text { göre etkin bir şekilde yerlileştirildiği } \\
\text { yanılsama. }\end{array}$ \\
\hline & $\begin{array}{l}\text { 3) Değişmezlik yanılsaması: } \\
\text { Doğal ve yapısal değişime dirençli } \\
\text { sayıldığından dolayı şimdiki zamanın } \\
\text { sonsuzlaştırıldığı, böylece içkin } \\
\text { bir değişim emri olarak şimdiki } \\
\text { zamanı yeniden oluşturan süreçlerin } \\
\text { belirsizleştirildiği yanılsama. }\end{array}$ \\
\hline \multirow[b]{2}{*}{ Temposentrizm } & $\begin{array}{l}\text { Aşağıdaki yanılsamaya sahip olan bir } \\
\text { tarihdışılık biçimi }\end{array}$ \\
\hline & $\begin{array}{l}\text { 4) Eş biçimli yanılsama: 'Yerlileştirilmiş' } \\
\text { ve 'somutlaştırılmış' şimdiki zaman, } \\
\text { şimdiki zamanın kendine özgü } \\
\text { özelliklerini farkına varmada hatayla } \\
\text { sonuçlanan tüm tarihsel sistemleri } \\
\text { 'eş biçimli' ya da 'benzeşik' olarak } \\
\text { göstermek için zaman içinde geriye } \\
\text { doğru tahmin edildiği yanılsama. }\end{array}$ \\
\hline
\end{tabular}


Hobson'un kronofetişizm ve temposentrizm kavramlarıyla açıklamaya çalışt1ğ1 temel yanılsamalar, metodolojik milliyetçiliğinde kendi içerisinde barındırdığı temel açmazları irdelenmesine imkân sağlayacaktır. Şu ana kadar iyi bir şekilde temellenmiş metodolojik milliyetçiliğe dayalı geliştirilen analizler, stabil olarak kimlikleri ele almakta, onları mekân ve zamana, tek bir dünya tarihine, evrensel geçerliliği olan tek bir zamana yerleştirmektedir. Ancak konstrüktivist duyarlılık şimdiye kadar analize tabi tutulan reddedilemez gelişim evrelerini, aktör tepkilerini, tam entegre olmuş toplum ve kültürlerini sorgulamaya yönelik bir bakış açısı sunmaktadır. Böylelikle "kültürün artık sadece zamansal süreklilik bir bütünlük veya yarı tutarlı bir 'sistem' olarak değil ayrıca oldukça farklı uğrakları ve yaşanılan etkinlik alanları içinde yorumlandığı metodolojik ve teorik yaklaşımlar" (Hall, 2017, s. 269) geliştirmenin imkânı yakalanmış olacaktır. Fine ve Chernilo'nun (2017) vurguladığı gibi modern ulus devletlerin başlangıcındaki ilkeler (devlet, hukuk, diplomasi, ulusal kimlik vb.) günümüzdeki ulus devletler sisteminin normatif kurulu ilkeleriyle basitçe aynı olamazlar.

\section{Çokkültürcülük Özelinde Milliyetçilik Çalışmaları İçin Metodolojik Öneri}

Metodolojik milliyetçiliğin kendi içerisinde barındırdığı temel açmazlardan kurtulabilmek için milliyetçilik çalışmalarında yeni bir metoda ihtiyaç olduğu açıktır. Çünkü bu paradigmanın temel ontolojik kabullerine yönelik eleştirel bakış, ulusun tarihselleştirilmesinin başka bir değişle heterojen zaman kavramlarını homojenleştirici, tek doğrusal ve evrimci varsayımlarıyla birlikte evrenselleştirici bir zaman algısına tabi kılarak yorumlanmasına karşı bir çözümü de beraberinde getirilmesini zorunlu kılmaktadır. Bu bağlamda konstrüktivist duyarlllık temelinde milliyetçilik okumalarında analizin nesnesi olan ulus devlete yönelik tartışmalarda “ diyalektik bütünsellik ilkesi”ne (Wagner, 1996 akt. Akyiğit, 2017) bağll geliştirilecek yöntem Tablo 3’te tasvir edildiği üzere bir çerçeve sunabilecektir. 


\section{Tablo 3}

Ulus Devlet Yapısının Diyalektik Bütünselliğe Bağlı Yöntemsel Düzeni (Akyiğit, 2017, s. 180)

\begin{tabular}{|l|l|l|l|}
\hline \multicolumn{2}{|c|}{ Ayrıșma } & \multicolumn{1}{|c|}{ İç Bağımlılı/Karșılların Birliği } \\
\hline Benzerlik & Farklılık & özerklik & Bağımlılık \\
\hline $\begin{array}{l}\text { İdeal Ulus-devlet Yapısı } \\
\text { (Temel Değerler, Siyasi } \\
\text { Doktrinler) }\end{array}$ & $\begin{array}{l}\text { Devletlerin Toplumsal, } \\
\text { Kültürel, Tarihsel, } \\
\text { Ekonomik Dinamikleri }\end{array}$ & $\begin{array}{l}\text { Etnisite, Din, Sosyo- } \\
\text { Kültürel Değerler }\end{array}$ & $\begin{array}{l}\text { Ulusal ve Yerel } \\
\text { Normlar }\end{array}$ \\
\hline \multicolumn{2}{|c|}{$\begin{array}{c}\text { Birey } \\
\text { (Devlet Yapısı) } \\
\text { (Makro Düzey) }\end{array}$} & $\begin{array}{c}\text { Toplum } \\
\text { (Mezzo düzey) }\end{array}$ \\
\hline
\end{tabular}

Metodolojik milliyetçilik kapsamında ulusdevlet tarafından idealleştirilen ulus, ulusal kimlik, devlet yapısına ilişkin temel ontolojik ve epistemolojik kabuller Tablo 3'de ifade edildiği üzere ayrışma ilkesiyle; ulusu oluşturan aktörlerin davranışlarına yönelik standardize edilen tepkilerini ise iç bağımlılık/karşıtların birliği ilkesiyle aşabilmek mümkün olabilecektir. Bununla birlikte milliyetçilik ve ulus devlet odaklı çalışmalarda böyle bir rehbere bağlı kalarak metodolojik okuma yapmaya özen gösterilmesi "Orta Doğu ve Balkanlar özelinde oryantalistik ve slavistik çalışmaların temelinde gelişen"11 (Aydın, 2000, s. 80) yaklaşımları aşabilmek için de bir başlangıç sağlayabilecektir. Kronofetiş ve temposentrik bakış açılarının sunduğu yanılsamalarla birlikte iki kutuplu millî tarih yazımından uzaklaşabilmek için merkez-periferi yolu takip etmeyen bir bakış açısı geliştirebilecektir. Diyalektik bütünsellik ilkesi, ayrışma ve karşıtların birliği ilkesiyle ulusun özgül ve evrensel olan arasındaki ayrımına dikkat çekmektedir. Bu metot aynı zamanda ulusların özgül tarihini araştırırken Liakos'un (2008a, s. 125) “çift yollu tarih" olarak ifade ettiği eğilimi de zenginleştirebilecektir.

Çift yollu tarih, birbiriyle örtüşen iki süreci çalışmak anlamı taşıyor. Yani ulusal şimdiki zamanın geçmişin bazı safhalarını benimseme sürecinin tarihsel hafızanın aktarım süreciyle örtüşme biçimi üzerine çalışmak. Kaybolanı (geri itilen veya bastırılan) geri almaya çalışan ilgili toplumsal güçler, onu evrimci bir anlatının belleğine dahil ederler. Fakat geçmiş, millî tarihe koşulsuzca teslim olmaz.

11 Oryantalistik ve slavististik çalışmalar, Orta Doğu ve Balkan aydınlarına kendi ülkelerinin tarihlerini ve kimliklerini (kültürlerini) tanıttı. Bu etki, yeni kimliklerin yaygınlaşmasının ve dolayısıyla öncelikle aydınlar düzeyinde panslavizmin, Arap milliyetçilik ve irredantizminin, Ermeni milliyetçiliğinin ve Türkçülük ile pantürkizmin neşet etmesinin altında yatan en önemli dayanaklardan biri olduğu ifade edilmektedir (bkz. Aydın, 2000, ss. 80-106). 
Geçmiş yeni ihtiyaçlara hizmet etmek için çağrıldığında, bu ihtiyaçları etkileyecek ve dönüştürecek yollar bulur. Yani geçmişle bugün arasında sıkı bir karşılıklı etkileşim vardır.

Bu şemanın anlaşılması için milliyetçilik çalışmalarında çift yollu tarih eğilimini diyalektik bütünsellik ilkesinin yöntemsel düzenin ana hatlarını Türkiye'de çokkültürcülük tartışmaları üzerinden örnekleyerek ele almak önemli bir başlangıç noktası olacaktır. Çünkü “Türkiye'nin sinırlı özgüllüğü bir tarafa, ulusdevlet kavramının kuşattığ toplumsal fenomenler bakımından asıl farklılık, gelişmiş kapitalist Batı toplumları ile çevre konumundaki Doğu toplumları arasındadır. Batı'da ulus devlet ve ideolojisi, ulusal burjuvazinin iç pazarı bütünleştirme çabasının bir ürünüyken Doğu'da genişleyen dünya kapitalizminin kendi dışına yansıttığı çelişkilerin bir dayatması olup genellikle dar aydın hareketlerinin ürünü olmuştur" (Aydın, 2000, s. 239). Tarihsel süreç içerisinde ulus devletlerde dayatmacı ikameci bir mantıkla yürütülen tüm tartışmalar neticesinde biriken ulusal sorunlar, 20. yüzyıldan itibaren özellikle son zamanlarda yaşanan göç ve insanların gitgide daha çok yer değiştirmesiyle, bildiğimiz zaman ve mekân uygunluğunu sorgulatır hâle gelmesine neden olmuştur. Belirsiz kimlikler, flulaştırılmış sınırlar, kesişim noktalarını vurgulayan mantık yürütme şekli ortaya çıkmıştır. "Uluslararası ötekilik", "diasporalar", "yersiz yurtsuzlaştırma" gibi kavramlar zaman, mekân ve kültür arasındaki uyumun zayıllatıldığına işaret etmektedir (Clifford, 1999 akt. Friese, 2015, s. 343). Bundan dolayı da metodolojik milliyetçiliğe bağlı olarak geliştirilen "asimilasyon", "kültürsüzleştirme", "senkretizm" gibi ulusları yaratma ve yönetme siyaseti yerini farklılıkların birarada yaşama siyasetini temsil eden "çokkültürcülüğü" gündeme getirmiştir.Bununla birlikte çokkültürcülük "modernliğin uzun yıllar boyunca kendi dışında olanı ötekileştirme, dışlama ve hor görme süreçleri ile kendisini ortaya koyan perspektifi karşısında postmodern teorinin temelinde ırkların, kültürlerin çoğulluğuna vurguda bulunarak hiçbir tarzın diğeri üzerinde egemenlik kuramayacağına" (Şan, 2020, s. 109) yönelik vurgusuyla ön plana çıkmıştır .ilk olarak çokkültürcülüğe dayalı kimlik politikaları "kültürel farklılıkların aktif olarak korunup sürdürülmesini açıkça arzulayan Fransa, Hollanda, İngiltere, Kanada ve ABD gibi devletlerin politikalarında görüldü" (Bonet ve Negrier, 2015, s. 12). Birleşik Devletler' deve Avrupa'da kendisini gösteren çokkültürcülük tartışması ise Türkiye'de yaklaşık 10 yıldır gündemdedir. Türkiye'nin "farklllık içinde birlik" ideali, ana akım liberalizm kapsamında çokkültürcü kimlik siyaseti ekseninde özellikle “Türk ulusal kimliği” temelinde tartışılmaktadır. "Türkiye'ye çokkültürcü toplum/ ulus modelini önerenler, her türlü etnik milliyetçilik/kültür ideolojisini aşarak vatandaşlığa dayalı bir milliyetçilik ideolojisini oluşturulabileceğini (...) vatandaşlık 
bağlarının belirli bir kültürel kimliği referans almaması gerektiği görüşündedirler" (Karadağ, 2005, s. 44). ${ }^{12}$ Ancak sanılanın tersine Birleşik Devletler başta olmak üzere Avrupa ülkelerinin toplum yapısına, jeopolitik konumuna bağlı olarak gösterilen kanıtların Türkiye'de aynı ölçüde ve bağlamlarda gerçekleştiğini düşünmek pek işlevsel değildir. ${ }^{13}$ Zira üzerinden çok geçmeden ABD, Kanada, Hollanda başta olmak üzere çokkültürcülüğe dayalı kimlik siyaseti, ulus devletlerin en önemli açmazları arasında tartışılmaya başlanmıştır. Çünkü metodolojik milliyetçiliğin etkisi, çokkültürcülüğün kategorilerinin kendisini zamansız ve evrensel olarak sunmas1, ulus devletlerin kendi sosyolojik, tarihî, jeopolitik deneyimlerini dikkate almadan yapılan çokkültürlü toplum tanımlamalarını beraberinde getirmiştir. Tarihin ve toplumsal bağlamın göz ardı edildiği çokkültürlü toplum tasviri ve ortaya konulan çokkültürcülük, ulus devletlerin özgül tarihine haksızlık etmekle kalmayıp etnokültürel grupların şimdiki zamanına dair problemli bir bakış açısı sunduğu görülmektedir. Çokkültürlülük kavramı Kymlicka (2015, s.53) tarafından ulusal ve etnik farklılıklardan söz etmek için ifade edilmiştir. Ayrı bir kültürü, ayrı bir dili ve tarihi paylaşan, ayrı soy bağları olan bir cemaat olarak 'ulus' ya da 'halk' ile eş anlamlı kullanmıştır. Dolayısıyla “özellikle Avrupa'da ve Amerika'da çokkültürlü bir toplum yapısını hazırlayan kitlesel göç hareketleri sonucu olarak ortaya çıkan çok kültürlü bir toplum yapısına uygun diye düşünebilecek olan çokkültürcülük, böylesi göç hareketlerinden etkilenmemiş olan Türkiye gibi ülkeler" (Gündoğan, 2005, s.112) açısından da ifade edilmesi verimsiz bir bakış açısı sunmaktadır. Çünkü Türkiye özelinde azınlıklardan ya da etnokültürel farklılıklardan bahsederken ABD veya Batı Avrupa ülkelerinde olduğu gibi tamamıyla birbirinden bağımsız, ortak bir tarihi paylaşmayan topluluklardan bahsetmek metodolojik milliyetçiğin dayattığ kronofetişizm ve temposentrizm kaynaklanan bir yanılgıdır. Türkiye'de ulus devlet özelinde çokkültürcü kimlik politikalarının etnokültürel gruplara yönelik toplum tasavvuru "zamanın, eksik bir şimdiki zaman ile tamamlanmış geçmiş arasındaki bölünmüşlüğünü ifade ederek bir yandan ulusun eşsizliğini diğer yandan da değişen bir dünya karşısında gecikmişliğini onaylar" (Liakos, 2008a, s. 124). Bu eksende özellikle Türk ulusal kimliği Batılılaşma, yerlilik ve modernleşme üzerine olan söylemlerde anayasal, modern düzenlemeler ile gelenekler arasında ikilik derinleş-

12 Bu konuyla ilgili ayrıntılı tartışma konuları için şu kaynaklara bakılabilir: Özdemir, 2005.

13 Bunun en önemli göstergeleri arasında $A B$ kapsamında uygulanan kimlik ve kültür politikaları yer almaktadır. Örneğin; Eker (2009), AB'nin dil politikaları ile ilgili mevcut şartlar ve uygulamaların, Türk dilinin, AB'nin resmî Farklılıkta Birlik mottosundaki 'farklılık' kavramının kapsamının dışında olduğuna yönelik çıkarımlarda bulunmaktadır. 
tirilerek farklı etnokültürel gruplarla birlikte yaşama deneyimi politikleştirilmektedir. Oysaki 19. yüzyıl ortalarından itibaren Türk ulusal kimliği Osmanlı tebaası için öngörülen kimlikle sürekliliğin yitirilmesi söz konusu olmamıştır. Osmanlıcılık, Türkçülük ve İslamcılık tartışmaları ekseninde kendisini gösteren ulusal kimlik, Osmanlı ethosu ile bir süreklilik oluşturma kaygısındadır (Kadığlu, 1999 akt. Bağlı ve Özensel, 2013, s. 32). Dolayısıyla kavramın içeriğine sadece Türkiye özelinde konstrüktivist bir duyarlılıkla bakıldığında bile "ana akım çokkültürcülüğün tarihdışılığı ve asosyolojikliği göze çarpmaktadır” (Akyiğit, 2018). Örneğin; Özensel (2013), Türkiye'de, çokkültürcü kimlik siyasetinin aşırı karmaşıklığının bilincine varılmasının önemini vurgulamak için çok kültürlüğün aksine kültürel birlikteliği ifade eden "halat kültür"den ${ }^{14}$ söz etmenin daha uygun olacağını vurgulamıştır. Çünkü "halat kültür" metaforu; "Türkiye'de birbirine geçmiş fakat birbirine geçen bu unsurların tamamı kendi özellikleriyle var olan ve bu sarmaşık hâlleriyle de güçlü bir unsuru temsil eden bir ögeyi” (2013, s. 15) ifade etmektedir. Bundan dolayı da Türkiye'deki kültürel çeşitliliğin ne "eritme potası"na (ABD) ne de "salata kasesi”ne (Kanada) benzetebileceğinin altı çizilmektedir. Özensel'in vurguladığı hâliyle "halat kültür" metaforu aracilığıyla çokkültürcü kimlik tartışmaları, diyalektik bütünsellik ilkesi bağlamında çözümlemeye tabi tutulduğunda net bir şekilde şunun ayrımına varılabilinir: Günümüzde metodolojik milliyetçiliğe dayalı bir okumayla Türk toplumuna yönelik tanımlamaların, çokkültürcülüğe bağlı idealleştirilen ulus devletin, Türkiye'de etnokültürel farklllıklar arasındaki ilişkileri ne oranda çözümsüzlüğe sürüklediği ortadadır. Bunun en yakın örneğini Türkiye'de özellikle Kürtlere yönelik siyasi ve demokratik bir çözüm amaçlamak gayesiyle ele alınan "Çözüm Süreci” akabinde gelişen siyasi, toplumsal sorunlarda görülmüştür. Bu tartışmaların gölgesinde "halat kültür" kavramı, çift yollu tarih çalışmalarını besleyebilecek bir dinamizm avantajını taşımaktadır. Metodolojik milliyetçilikle evrenselleştirilen ve yapısüreklilik dikotomisinin önüne geçerek ulus devlet, ulusal kimlik tartışmalarında süreçsel niteliğe dikkat çekmektedir. "Halat kültür" kavramı metodolojik

14 Ertan Özensel (2013) farklılıkların bir arada barış ve huzur içinde yaşaması adına dünya da bir model olarak var olan “çokkültürlülüğün” genelde Doğu toplumlarında özelde de Türkiye'de kendine uygulama imkânı bulup bulamayacağını sorguladığı "Doğu Toplumlarında ve Türkiye’de Birlikte Yaşama Arayışı: Çokkültürlülük Mü? Yoksa Yeni Bir Model Mi?” başlıklı makalesinde, çokkültürlülük yerine "halat kültür” kavramının tanımlamasını yaparak Türkiye özelinde yeni bir model geliştirilmesinin gerekliliğini vurgulamıştır (bkz. Özensel, 2013). Akyiğit (2017) ise Türkiye'de liberal çokkültürcülük politikalarına karşılık "farklılık içinde birlik idealinin barış ve demokratik bir süreç içerisinde gerçekleşmesini sağlayacak nasıl bir kimlik siyaseti geliştirilmelidir?” sorusunun tartışıldığı doktora tez çalışmasında "halat kültür” kavramını referans noktası alarak Türkiye’nin gizli habitusunu açığa çıkartılmasını sağlayacak Türkiye için yeni bir kimlik siyasetinin ontolojik ve epistemolojik kabullerini temellerini tartışmıştır. 
olarak Türkiye özelinde Batı Avrupa ülkeleri temelli gelişen yayılmacı yegâne ulusçuluk anlayışının ötesinde tarihsel güzergâhların çoğulluğuna, kavramların çok anlamlılığına vurgu yapılabilmenin imkânını sağlamaktadır. "Halat kültür” anlam itibarıyla hem ideolojik hem duygusal bir olgu hem bir zihin durumu hem de toplumsal bütünleşmenin bir türüdür. "Bir arada yaşamak" sürekli yapılacak düzenlemeleri, esnek bir durumu ifade etmektedir. Buna karşılık çokkültürcülük düşüncesi daha çok kültürler arasındaki ilişkilerin düzenlenmesine gönderme yapmaktadır. Bir arada yaşama, ne kimlik ne de farklllıkların yönetimi sorununun çözümlenmediğine ve sürekli başvurulan topluluk, bölge ya da iletişim gibi mucize kavramlara yönelmenin artık kolaylıkla mümkün olmadığına işaret etmektedir. Türkiye'de kültürel birlikteliği temsil eden "halat kültür"den söz etmek bu açmazı kökten çözmese de çokkültürcülüğün aksine diyalektik bütünsellik ilkesi gereği her şeyi 'yeniden yazmak' gerektiğini ifade etme şansını sunmaktadır. Çünkü "etnisite, ulus üzerine yeni bir söylem, yeni bir ulus ve milliyetçilik ideolojisinin formüle edilmesidir yani yeni bir millet/ulus tasavvurudur" (Aktürk, 2015, s. 27).

Sonuç itibarıyla Türkiye'de milliyetçilik tartışmalarının temelini oluşturan ulus, ulusal kimlik kavramlarına, Türk toplumunu oluşturan kültürel örüntülerin kendi içinde özerk ve iç bağımlılık durumlarını açığa çıkartabilen bir metot ile bakıldığında farklı kavramlar bağlamında tartışmaları açığa çıkartabilmenin mümkün olduğu görülmektedir. Halat kültür, Türkiye özelinde, temelde daha güçlü bir güç veya etnik hegemonyadan ziyade daha yüksek bir sorumluluk algısı ve çağrısı yapmaktadır. "Millî duyguların milliyetçilik olmadığına"(!) (Jaffrelot, 2018) yönelik vurguyla birlikte metodolojik milliyetçiliğin "ulus olma" bilincinde geçerli gördüğü ontolojik ve apriori kabullerin ötesinde bir tanımlamayı içererek "kim olduğumuz"a ilişkin deontolojik bir noktada duran bakış açısı sunmaktadır. Halat kültür esasında metodolojik milliyetçiliğin tanımladığı kültürel örüntülerin aksine kültürün bağlamsal ve kesişimsel özelliklerine dikkat ederek yeniden gözden geçirilmesine yönelik bir yol haritası sunmaktadır. Çünkü diyalektik bütünsellik ilkesiyle bakıldığında kültür, "cemaatten daha karmaşık bir yaşama biçimidir, toplumdan daha semboliktir, ülkeden daha çağrışımcıdır, vatandan daha az vatanseverdir, devlet aklından daha retoriktir, ideolojiden daha mitolojiktir, hegemonyadan daha az homojendir, vatandaştan daha az merkezlidir, özneden daha kolektiftir, kibarlıktan daha ruhsaldır, kültürel farklılıkların ve tanımlamaların ifadesinde, herhangi bir hiyerarşik veya iki unsurlu toplumsal husumet yapilanmasında temsil edilebileceğinden daha melezdir" (Bhabha, 2016, s. 265). Böylelikle metodolojik milliyetçiliğin doğallaştırdığı ulus oluşumundaki süreçsel niteliğe dikkat çekmektedir. Bunun için konstrüktivist bir duyarlılıkla diyalektik bütünsellik ilkesi aracılığıyla Türk ulusu- 
nun icadında işletilen ayrıntıların tarihsel olarak kavramsallaştırılması gerektiğini gösterebilmektedir. "Ulusun dişsal ampirik unsurlarla değil bir ulusu oluşturan bireylerin içselleştirdiği unsurlarla” (Bauer 1978 akt. Liakos, 2008, s. 31) ele alınarak tanımlanmasının önemini hatırlatmaktadır. Bu bakış açısı konstrüktivist duyarlılığa bağlı diyalektik bütünsellik ilkesiyle birlikte Türkiye özelinde Avrupamerkezci gelişen metodolojik milliyetçilik ve ulus devlet okumalarının ötesine geçebilmeyi sağlayarak siyasallığın felsefesinin yeniden gözden geçirilmesini mümkün kılabilecektir. Bu metot aynı zamanda Smith'in (2017, s. 181) etnosembolik yaklaşımda altını çizdiği millet ve milliyetçilik tartışmalarına toplumsal ve kültürel bir bakış açısı sunmaktadır. Böylelikle siyasi, ekonomik faktörlere odaklanan modernist yaklaşımlar tamamlanabilecektir.

Kuşkusuz "milliyetçilik 18. yüzyılda yayılmaya başladığında, yeni kimliklerin ortaya çıkışı artık bir orijinal yaratım sonucu olmaktan çıkmış, hâlihazırda var olan bir fikrin ithal edilmesi halini almıştır. 18. yüzyıl Avrupa'sında İngiltere'nin hâkimiyeti ardından da dünyada batının hâkimiyeti, milliyetçiliği genel kural hâline getirmiştir. Çekirdek Batılı toplumların nüfuz alanı genişledikçe Batı'nın merkez olduğu üstün toplum sistemine ait olan ya da ona katılmayı isteyen toplumların millet haline gelmekten başka seçenekleri yoktu" (Greenfeeld, 2017, s. 35). Ancak "milliyetçilik her zaman bir söylem koalisyonu olmuş; liberalizm, muhafazakârlık, faşizm ya da sosyalizm gibi farklı ideolojilerin her birine eklemlenmekte zorluk çekmemiştir" (Kerestecioğlu, 2016, s. 310). Bundan dolayı olsa gerek Türkiye Cumhuriyeti kurulduğundan günümüze kadar sağ, sol ve liberal ideolojilerin ürettiği "parçalı", "eklektik" milliyetçilik ve Türk toplumu tasavvurları, ülkenin temel sorunlarının çözülmesinde yetersiz kaldığından Türk modernleşmesinin buhranlarından kendisini kurtaramamıştır. Ancak tüm bunları aşarak "günümüzde temel hak ve hürriyetleri teminat altına alan, anayasal vatandaşlık esasına dayalı demokratik bir düzen ile ortak tarih, kültür ve medeniyet mirasımızı referans kabul eden bir siyasi düzen toplumsal model kurmak (...) evrensel değerlerle tarihî birikimi, demokratik hak ve özgürlükle ahlakı, şeffaflı ve hesap verebilirlikle kültür ve medeniyet mirasını temsil edebilen" (Kalın, 2013, s. 20) bir Türkiye'nin toplumsal muhayyilesini yapabilmek merkezî öneme sahiptir. Toplumsal muhayyile kavramı "tarihle biyografiyi bir arada kavrama" (Mills, 2007, s. 15), "geçmiş yaşantılara özgü ögelerle şimdiki yaşantı arasında bağ kurma” (TDK, 1994) manasıyla kullanılmaktadır. Böyle bir toplumsal muhayyile için "halat kültür" kavramı elverişli imkânlar ve açılayıcı bir yol sunabilir. Bu anlamıyla da muhayyile sadece "fikirler yahut kurumlar üzerinde durmaz, geniş manada bir toplumun 'praxis'ini yani varlık ve hayat pratiklerini anlamaya ve anlamlandırmaya (Taylor, 2004) çalışırken birlikte 
düşünmek ve hissetmek manasına karşılık” gelmektedir (Kalın, 2013, s. 21). Böyle bir düşünme ve bakış açısı pratiği içerisinde "halat kültür" kavramı ise Türk toplumunun "farklılıkla bir arada yaşama deneyiminin" kusurlu yanlarını örtebilecek yeniden tasavvur edebilecek milliyetçilik okumasının bağlamını oluşturabilecektir. Bunu yapabilmek önemlidir. Çünkü Greenfeld'in (2017, s. 13) isabetli tespitiyle modern dünyada politika, milliyetçilik tarafından oluşturulmuştur. Bundan dolayı da bu dünyada milliyetçilik, düşünme ve duyuş tarzımızı, gerçekliği görme ve deneyimleme tarzımızı şekillendirmektedir. Bilinçlerimizin 'millî' olarak inşa edildiğini ve bu açıdan hayatımızda oynadığı rolü düşündüğümüzde milliyetçiliği anlamak için elimizden geleni yapmamız gerekmektedir.

\section{Sonuç}

Avrupa tarihinin başından sonuna kadar Avrupa düşünün, kimliği aynı dünyaya karşılıklı aidiyet olarak değil aynın aynıyla ilişkisi, varlığının ortaya çıkması ve öncelikle kendi varlığında ya da hatta kendi aynasında belirmesi olarak kavrama eğilimi taşıdığı açıktır. ${ }^{15}$ Konstrüktivist duyarlılığa bağlı ulus devlet ve milliyetçilik çalışmaları tam anlamıyla bu kavrama eğilimini aşma çabasındadır. Metodolojik milliyetçilikle yaygınlaştırılan ana tema; analiz sürecinin ve kültürlerarası karşılaştırılmadan ayrıştırılmış, homojen oldukça iyi entegre olmuş etnisiteler şeklinde kurgulanmasıydı. Özne ve nesne arasındaki epistemolojik kırılma mekânsal tarihsel uzaklık ile kültürel farklılık arasındaki uyuma dair farazilere dayanacaktı. Milliyetçiliğin tüm ulus, vatan, aidiyet, kimlik, devlet gibi tüm çıktıları, özerk araştırma alanları inşa etmek için kullanım aracı sunmaktadır. Bundan dolayı metodolojik milliyetçiliğe dayalı olarak geliştirilen ulus devlet çözümlemelerinde inceleme alanında farklılıklara yönelik vurgu yoktur. Kültürel formlar ve muhayyel alan, diller ve semboller üzerine aşırı vurgu söz konusudur. Friese'nin (2015, s. 341) vurguladığı gibi araştıran "özne” ile "nesne” arasındaki bu kopukluk, “öznelerin” -yani ulusların- bizatihi kendisinin analiz edilebilir kimliğe bürünmesini sağlamıştır. Bu kimlik olmadığı takdirde ise bu süreç oldukça şüpheli görülecektir ya da tarihsel süreçte kaçırılmış fırsatlar üzerine söylemler geliştirilecektir. Böylelikle "içerik ne ise o kılığa bürünebilecek bir tür 'hemen hazır soyut biçim', imge medeniyetinin ve bu medeniyetin gerçeklikler ve kurgular arasında ilişkiler kurmasının tipik bir 
özelliği" (Mbembe, 2019, s. 15) tasarlanmış olacaktır. Buna paralel olarak metodolojik milliyetçiliğe dair geliştirilen klasik anlatılarda Türk modernleşme projesi örneğinde görüldüğü üzere modern/geleneksel, merkez/taşra, Batı/Doğu, laik/dinci ve ilerici/gerici gibi bizzat modernist projenin kurucusu ikililikler aracılığıyla aktarılmaktadır. Bu ikililikler, yerel söylemlere sızmakla kalmamıştır. Osmanlı ve Türk tarih yazımında analitik kategoriler olarak hâlen geniş bir kullanıma sahiptir. Tüm bunların ötesinde bu çalışmada kısaca tartışılmaya çalışıldığı üzere öznel tarihi yok sayan sosyolojik muhayyileden yoksun olan bu anlatıların ötesinde konstrüktivist yaklaşım duyarlılığında milliyetçilik konusunu tartışmak önem arz etmektedir. Türkiye'de milliyetçilik tartışmaları; toplumun özel ve kolektif kültürel örüntüleri, deneyimleri bağlamında çeşitli hissiyatlar, değerler arasındaki etkileşim dinamikleri, süreklilikler ve kopuşlarla birlikte dikkate alınarak anlaşılabilecektir. Modernist dil ve metodolojik milliyetçilik özellikle toplumsal ritüelleri, öznel deneyimleri görmekten yoksun olduğu için ulus ve ulusal kimlik tanımlamalarında halkın siyasal ve düşünsel bilincini, cemaat anlayışını, kültürünü, dilini ve dinini açılamaya elverişli değildir. Bugünün milliyetçilik tartışmalarının merkezini oluşturan azınlık, etnik grup olarak tasavvur edilen toplulukların kendi iç doğası, akışkanlığı ve etkileşime açı olan yönlerini metodolojik milliyetçiliğin temel kabulleri görmezden gelmektedir.Bunun en yakın örneğini çokkültürcülük tartışmaları ve Türkiye özelinden ilerleyen tartışmalarda görmek mümkündür. Tüm bu yanılsamaların üstesinden gelebilmek için metodolojik milliyetçilik anlatılarının tasavvur ettiği "normatif değerlerimizi ya da totolojik varsayımlarımızı bir kenara bırakarak" (Buçukcu, 2020, s.195) çalışmalara yön vermek önemlidir. Buradaki güçlük, ideolojik sosyopolitik normalleştirme politikalarına hizmet etmeden bir yaklaşımla birlikte yöntem geliştirebilmekten geçmektedir. Çalışma kapsamında ifade edilen analiz ve eleştiriler, milliyetçilik çalı̧̧malarında geliştirilecek yöntemlerin tümdengelim yerine tümevarımsal bir tarzda formüle edilmesinin, yaklaşımların ise kronofetiş ve temposentrik yanılsamalardan arındırılması gerekliliğinin önemli olduğunu göstermektedir. Aynı zamanda çift yollu tarih eğilimiyle de yeniden değerlendirmeye tabi tutulacak kavramların değişkenlik, akışkanlık yerine sınırları; dinamik, geçirgenlik yerine statiği içermemesi gerektiğinin altı çizilebilecektir. Bununla birlikte milliyetçi anlayışa ve ulus devlet, ulusal kimlik, kültürel farkl1lık kimi konular ele alındığı zaman kültür ya da ulus yalnız öncelikli olarak milliyetçi bir çerçevede ele alınmak zorunda değildir. Metodolojik milliyetçiliğe bağlı tasavvur edilen ulus dolayısıyla halk, kimlik ve kültürler sabit değildirler, şeyleştirilmemelidirler. Çokkültürcülük örneğinde kısaca değinilmeye çalışıldığı üzere Türk ulusunun farkllıkla birarada yaşama deneyimine ilişkin halat kültür tanımlaması, Gellner'in ve Anderson'un 
ulus ve ulusçuluk tartışmalarında bugünün geçmişten radikal bir biçimde bir kopuşu temsil ettiğine yönelik tezlerinin dikkatli bir şekilde sorgulanması gerektiğini tekrar hatırlatmaktadir.

Sonuç olarak konstrüktivist duyarlılığa ve diyalektik bütünsellik ilkesine bağlı olarak metodolojik milliyetçiliğin epistemik kabullerini yeniden okuma çabası, dört farklı dönüşümü kendi içerisinde barındıracaktır: İlki, ulusların kendi hayatlarını yorumladıkları referans noktalarını (din, etnik, kültür, tarihsel bağlam, mekânsal uzam gibi) mercek altına alarak, kendilerini ifade ettikleri ve eylemlerini anlamlandırdıkları dili üretmeleri noktasında fikirsel referanslara odaklanmayı sağlayacaktır. İkincisi, bireyleri hem sosyal hem de ulusal aktörler olarak yaşadıkları ve faaliyet gösterdikleri sosyal evren tarafından içselleştirilen içkin özneler olarak okuyabilecektir. Böylelikle idealleştirilen milliyetçilik söylemlerine bağlı eklemlenerek okunan bir ulus tanımlamasının ötesine geçilmesi mümkün olacaktır. Üçüncüsü, her ulusu oluşturan aktörlerin özsel menfaatlerinin olacağı, bu menfaatlerin toplumsal etkileşime bağlı olarak içsel gelişebileceğini dikkate almayı sağlayacaktır. Dördüncüsü, bireylerin ulusal aktörler olarak içinde bulunduğu ulusdevlet özelinde geliştireceği eylemlerinin kendi hayatlarının ve fikirsel durumlarının ürettikleri, etkileşim içerisinde oldukları toplumsal yapının dokusuna nasıl nüfus ettiğiyle ilgilidir. Milliyetçilik çalışmalarında metodolojik milliyetçiliğin içerdiği tüm bu teolojik ve politik güç rasyonelleştirmelerinden sıyrılmanın başlangıç noktasını ise karşılaştırmalı tarih, tarihsel sosyoloji geleneğini benimseyen etnosembolizmle birlikte konstrüktivist duyarlılığın temelinde gelişen diyalektik bütünsellik ilkesinin metodolojik ilkeleri, incelikli ve bütüncül bir rehber oluşturabilecektir. 



\title{
Methodological Criticism of Nationalism
}

\author{
Handan Akyiğit
}

The dreadful consequences of the events that took place in the early 1990s in former Yugoslavia, considered as a sudden burst of nationalism, triggered the debate on the decline of nation-states after the initial confusion in social sciences about the nature and scope of globalization. Evidently, the issue of multiculturalism, which includes redefining nation-states, has a large share in these debates. The most important issue to emerge with multiculturalism is the discourse questioning national culture in particular. Starting to question national cultures is important. This is because, contrary to Fukuyama's (1993) proposition that we had entered the "end of history " after Cold War's end in 1991, this period contains the struggle for "the realization of differences," marked by new debates on nation-states and nationalist movements along the axis of cultural identity demands and conflicts. All the movements that took place on the axis of these demands for cultural identity had caused the issue of culture, the most important epistemological assumption of nationalism, to be opened to discussion. It caused the phenomenon of national culture to turn into a conceptual vision that had emerged on religious and ethnic grounds. Discussing these debates in relation to the multiculturalist identity politics that had developed with the epistemic assumptions of methodological nationalism has become commonplace. Turkey is not removed from this process, either. In the

(iD) http://orcid.org/0000-0002-7619-1638 
discourse on multiculturalism, the phenomenon of national culture, especially in terms of minorities and religious and ethnic identity, particularly in Western Europe and to a similar extent in Turkey, have been widely discussed, with many studies having been done on this topic. However, the discourse on multiculturalism has not produced any successful results for establishing a stable and safe world. This is evident, especially when looking at the ethnically based nationalist movements and conflicts in Scotland, Catalonia, and Quebec. Movements based on micronationalism in the context of nation-states have started to diversify. This situation, which is being encountered in its most recent form, shows that the epistemic assumptions of methodological nationalism should be questioned in studies on nationalism and that the illusions forming the basis of assumed national cultures in particular should be revealed.

The main thesis of this study is to explain the methodological contexts of the "rope culture" metaphor in the context of Turkey by getting rid of the methodological understanding of nationalism in order to bring this vision to life. In doing so, the basic concepts of two fields in particular are used: constructivist theory and the principle of dialectical holism. The main issue discussed when making use of constructivist theory is the epistemic contexts of methodological nationalism. In this context, the article discusses the primordialist and modernist theories that form the basis of methodological nationalism, basically stating that methodological nationalism erroneously assumes that all societies under the influence of the outside world assimilate nationalism through similar measures and processes and become nation-states. The foundations of methodological nationalism, historically unique and accepted as the milestone of Western configurations, have been discussed through Hobson's (2015) concepts of chrono-fetishism and tempo-centrism. The constructivist approach provides an opportunity to overcome the basic illusions included in methodological nationalism which Hobson tries to explain through the concepts of chrono-fetishism and tempo-centrism. This is because the constructivist approach, contrary to methodological nationalism, offers a different opening towards the nature of nationalism, especially through different institutional and cultural characteristics. Therefore, looking not at the normative structure of nation states and how this affects states' social identities but at the contexts in which the cultural patterns of the nation are formed becomes possible.

Constructivist sensitivity offers a perspective for questioning the irrefutable developmental stages of methodological nationalism, actor reactions, and so-called fully integrated societies and cultures. In this way, constructivist sensitivity ques- 
tions the emphasis on homogeneity with the powerful, symbolic, and influential sources of cultural identity integrated with the national identity envisioned within the nation. As a cultural force, constructivist sensitivity can serve to go beyond the historicism that has dominated the debates on nations.

Evidently a new method is needed in studies on nationalism in order to avoid the basic dilemmas that methodological nationalism entails. In this context and on the basis of constructivist sensibility, the method developed based on the dialectical holism principle (Wagner, 1996, as cited in Akyiğit, 2017) in discussions on nation-states, which is the object of analysis in nationalism readings, provides the framework.

While making use of sources on the principle of dialectical holism, the main issue this article addresses will be the problem of culture in historical analysis and thus in methodological nationalism. The main reason for focusing on the issue of culture in particular is the recent radicalistic reactions that have brought national differences to the fore again, especially in European countries, and that proceed in a distinctly discriminatory path. Therefore, the study examines the problem of culture in methodological nationalism through examples using discussions on multiculturalism. Using the illusions offered by the chrono-fetishistic and tempocentric perspectives, a perspective that does not follow the center-peripheral route can be developed in order to move away from bipolar national historiographies. The principle of dialectical holism draws attention to the distinction between particular and universal nations using the principle of separation and unity of opposites. This method can also enrich the trend Liakos (2008a, p. 125) referred to as "twoway history" while investigating nations' specific histories. Therefore, the article considers evaluating the two-way history trend in nationalism studies by dealing with the outline of methodological order for the principle of dialectical holism using examples regarding the debate over multiculturalism in Turkey as an important starting point. This is because the national problems that have accumulated since the 20th century as a result of all the discussions carried out on nation-states in the historical process by imposing substitutional logic, especially with the recent immigration and displacement of more people have made the compatibility of time and place as we had known questionable. For this reason, the politics of creating and managing nations through certain methods such as assimilation, ex-cultivation, and syncretism, which developed based on methodological nationalism, have brought multiculturalism to the agenda and represents the politics of the coexistence of differences. The multiculturalism debate, which shows itself in the United States 
and Europe, has been on the agenda in Turkey for nearly 10 years. Turkey's ideal of unity in diversity has been discussed on the basis of the Turkish national identity, especially in the context of multiculturalist identity policies within the mainstream liberal axis. However, contrary to popular assumption, thinking the evidence that is indicated based on social structure and geopolitical position mainly in the United States and Western and European countries to be relevant to the same extent and in the same context in Turkey is not very functional. This is because identity politics based on multiculturalism, especially in the USA, Canada, and the Netherlands, starting to be discussed not long after among the most important dilemmas of nation-states and because the effect of methodological nationalism has brought about definitions of multicultural society without taking into account nation states' sociological, historical, or geopolitical experiences as the categories of multiculturalism, presenting themselves as timeless and universal. The depiction of a multicultural society that ignores historical and social contexts and the multiculturalism that has emerged from this not only do wrong to the specific history of nation-states but also poses a problematic perspective on ethno-cultural groups in the present. For example, when talking about minorities or ethno-cultural differences in the Turkish context, mentioning them as if they are completely independent from each other and do not share a common history, which is often the case in the USA and Western European countries, is among the most fundamental misconceptions stemming from chrono-fetishism and tempocentrism that methodological nationalism imposes.

Özensel (2013) emphasized talking about rope culture, which expresses cultural unity contrary to multiculturalism, to be more appropriate because being aware of the extreme complexity of multiculturalist identity politics in Turkey has importance and because the metaphor of rope culture expresses "all of those elements meshing with their own properties as an item representing a strong element, with this intertwining in Turkey" (2013, p. 15). Therefore, cultural diversity in Turkey is emphasized as being incomparable to the "melting pot" (the USA) nor the "salad bowl" (Canada). When analyzing the multicultural identity discussions in the context of the principle of dialectical holism through the metaphor of rope culture as emphasized by Özensel, the following can be clearly distinguished: With a reading based on methodological nationalism, the current definitions of Turkish society and the multiculturalism-linked idealized nation-state obviously drag the relationship between the size of ethno-cultural differences to a deadlock. The most recent example of this is observed in the political and social problems following the "Resolution Process," which had aimed at a political and democratic resolution 
for Kurds in Turkey in particular. In the shadow of these discussions, the concept of rope culture has a dynamic advantage as it can feed two-way history studies. By avoiding the structure-continuity dichotomy that methodological nationalism has universalized, the rope culture concept draws attention to the processual nature of nation-state and national identity discussions. In the context of Turkey, the concept of "rope culture" provides the opportunity to emphasize the multiplicity of historical routes and polysemy of concepts beyond the expansionist uniquenationalist understanding that is methodologically based on Western and European countries. Rope culture is both an ideological and emotional phenomenon, a state of mind and a type of social integration. Coexistence refers to continuous arrangements, a flexible situation. On the other hand, the idea of multiculturalism instead refers to regulating intercultural relations. Coexistence implies that neither the problems of identity nor managing differences has been resolved and turning to miracle concepts such as community, region, or communication, which are constantly referenced, is no longer easily possible. Although discussing rope culture, which represents cultural unity, does not radically resolve this dilemma, it offers the chance, unlike multiculturalism, to state that everything should be rewritten in accordance with the principle of dialectical holism.

When examining the concepts of nation and national identity, which has formed the basis of the nationalism debate in Turkey, using a method that can reveal the self-autonomous and internally dependent conditions of cultural patterns that make up Turkish society, revealing discussions in the context of different concepts is likely to be seen. Rope culture, particularly in Turkey, basically calls for a higher sense of responsibility rather than a stronger power or ethnic hegemony. By ensuring one goes beyond the readings of nation-state and methodological nationalism developed in a Eurocentric form through the dialectical holism principle based on constructivist sensitivity, this concept makes reconsidering the philosophy of the political possible. This method also provides a social and cultural perspective to the nation and nationalism debates Smith (2017, p. 181) highlighted in the ethno-symbolic approach, thus being able to complete the modernist approaches focusing on political and economic factors.

In conclusion, the effort to reread the epistemic assumptions of methodological nationalism with a basis on constructivist sensitivity and the principle of dialectical holism will involve four different transformations. First, focusing on the reference points (religion, ethnicity, culture, historical context, locational space, etc.) that nations interpret in their own lives will enable them to focus on the intellectual 
references at the point of producing the language they express and making sense of their actions. Second, individuals will be able to be studied as immanent subjects internalized by the social universe in which they live and operate as both social and national actors. In this way, going beyond the definition of nation that is studied by articulating based on idealized nationalist discourses will become possible. Third, this will allow taking into account the fact that the actors who make up every nation will have inherent interests and that these interests can develop internally depending on social interaction. The fourth transformation is about how the actions that individuals develop as national actors in the nation-state in which they are involved penetrate into the fabric of the social structure that their lives and intellectual situations produce and interact with. The starting points for getting rid of all these theological and political power rationalizations contained in methodological nationalism in nationalism studies are comparative history, an ethno-symbolism that adopts the tradition of historical sociology tradition, and the methodological principles of a dialectical holism developed on the basis of constructivist sensibility, and these can form a nuanced and holistic guide.

\section{Kaynakça}

Aktürk, Ş. (2015). Almanya, Rusya ve Türkiye'de etnisite rejimleri ve milliyet. İstanbul: İstanbul Bilgi Üniversitesi Yayınları.

Akyiğit, H. (2017). Türkiye'de ulus devletin dönüşüm sürecinde etnik kimlikler: Sakarya ili örneği. Yayımlanmamış doktora tezi. Sakarya: Sakarya Üniversitesi.

Akyiğit, H. (2018). Entegrasyon göç ve çokkültürcülük tartışmalarında 'kronofetizm'i ve 'temposentrizm'i aşmak. Yayınlanmamış sözlü sunum. 2. Uluslararası Göç ve Mültecilik Kongresi, Düzce.

Amin, S. (2007). Avrupa-merkezcilik bir ideolojinin eleştirisi. M. Sert (Çev.). İstanbul: Chiviyazıları Yayınevi.

Anderson, B. (2000). Hayali cemaatler. İ. Savaşır (Çev.). İstanbul: Metis Yayınları.

Aravamudan, S. (2012). Enlightenment orientalism. Revisiting the rise of the novel. Chicago: Universty of Chicago Press.

Armstrong, J. (1982). Nations before nationalism. Chapel Hill Univesity of Nort Carolina Press.

Aydın, S. (2000). Modernleşme ve milliyetçilik. İstanbul: Gündoğan Yayınları.

Bağlı, M. ve Özensel, E. (2013). Çokkültürlü vatandaşlık. Konya: Çizgi Kitabevi.

Barth, F. (2001). Etnik gruplar ve sınırları. A. Kaya ve S. Gürkan (Çev.). İstanbul: Bağlam Yayınları.

Bauer, O. (1978). The nationalities question and social democracy. T. Bottomore, P. Goode (Ed.). AustroMarxism içinde (ss.117-107). Oxford University Press.

Baumann, G. (1999). Çokkültürlülük bilmecesi. I. Demirakın (Çev.). Ankara: Dost Kitabevi.

Bernal, M. (2016). Kara Atena. Ö. Buze (Çev.). Kaynak Yayınları.

Bhabha, H. K. (2016). Kültürel konumlanış. T. Uluç (Çev.). İstanbul: İnsan Yayınları.

Bonet, L. ve Negrier, E. (2015). Ulusal kültürlerin sonu mu? Çeşitlilik sinavında kültür politikaları. I. Ergüden 
(Çev.). İstanbul: İstanbul Bilgi Üniversitesi Yayınları.

Buçukcu, Ö. (2020). Milliyetçilik. İstanbul: Ketebe Yayınları.

Calhoun, C. (1997). Nationalism. Minneapolis: University of Minnesota Press.

Certeau, de M. (2008). Gündelik hayatın keşfi-1. L. Arslan-Özcan (Çev.). Ankara: Dost Kitabevi.

Clifford, J. (1999). Routes: travel and translation in the late twentieth century, Cambridge, MA: Harvard University.

Dahbour, O. ve Ishay, M. R. (1995). The nationalism reader Atlantic highlands. Humanities Press International.

Delanty, G. ve Işın, E. F. (2017). Tarihsel sosyolojiyi yeniden konumlandırmak. G. Delanty ve E. F. Işın (Ed.). Ü. Tatlıcan (Çev.). Tarihsel sosyoloji içinde (ss. 15-27). İzmir: Islık Yayınları.

Eker, S. (2009). Avrupa Birliği'nin yeni mottosu 'farklılıkta birlik' ve Türkçenin 'farklılıkta birlik'teki yeri. Bilig, 49, 35-58.

Friese, H. (2015). Avrupa'nın ötekiliği: Kozmopolitik ve kültürel birliklerin inşası. G. Delanty (Ed.). F. Bulut (Çev.). Şarklı globalleşme: Geçmişi ve bugünü, doğu ve batının ötesinde Asya ve Avrupa içinde (ss. 333-350). İstanbul: Matbu Yayınları.

Fine, R. ve Chernilo, D. (2017). Yakın dönem tarihsel sosyolojide sosyal sınıflar ve uluslar. G. Delanty ve E. F. Işın (Ed.). Ü. Tatlıcan (Çev.). Tarihsel sosyoloji içinde (ss. 379-402). İzmir: Islık Yayınları.

Fukayama, F. (1999). Tarihin sonu ve son insan. Z. Dicleli (Çev.). İstanbul: Gün Yayıncılık.

Gauchet, M. (2013). Yurttaşını arayan demokrasi. Z. Savaşçın (Çev.). İstanbul: İletişim Yayınları.

Geertz, C. (1973). The interpretation of cultures: Selected essays. New York: Basic Books.

Gellner, E. (1992). Uluslar ve ulusçuluk. B. Ersanlı-Bahar ve G. G. Özdoğan (Çev.). İstanbul: İnsan Yayınları.

Greenfeeld, L. (2017). Milliyetçilik moderniteye giden 5 yol İngiltere, Fransa, Rusya, Almanya ve Amerika örnekleri. A. Yılmaz (Çev.). İstanbul: Alfa Yayınları.

Gündoğan, A. O. (2005). Türkiyelilik ve çokkültürlülük. M. Ç. Özdemir (Ed.). Çokkültürlülük ve Türkiyelilik içinde (ss. 108-114). Ankara: Tekağaç yayınları.

Habermas, J. (2002). Öteki olmak öteki ile yaşamak. İ. Aka (Çev.). İstanbul: Yapı Kredi Yayınları.

Hall, J. A. (1993). Nationalisms: Classifed and explained. Daedalus.

Hall, J. R. (2017). Kültür tarihi öldürür. G. Delanty ve E. F. Işın (Ed.). Ü. Tatlıcan (Çev.). Tarihsel sosyoloji içinde (ss. 249-276). İzmir: Islık Yayınları.

Halliday, F. (2015). Bir uluslararası sosyolojiye doğru. S. Hobden ve J. M. Hobson (Der.). M. L. Karadere (Çev.). Uluslararası ilişkilerin tarihsel sosyolojisi içinde (ss. 345-373). Sakarya: Sakarya Üniversitesi Kültür Yayınları.

Harik, I. F. (1972). The ethnic revolution and political integration in the middle east. International Middle East Studies. 3, 303-23.

Hassner, P. (2018). Uluslararası ilişkilerde milliyetçilik ve şiddet. A. Dieckhoff ve C. Jaffrelot (Der.). D. Çetinkasap (Çev.). Milliyetçiliği yeniden düşünmek-kuramlar ve uygulamalar-içinde (ss. 261-281). İstanbul: Metis Yayınları.

Hayes, C. J. H. (1960). Nationalism: A religion. New York: Macmillan.

Heywood, A. (2006). Siyaset. B. Kalkan (Ed.). Ankara: Liberte Yayınları.

Hobson, J. M. (2015). Tarihsel sosyolojiyi yeniden uluslararası ilişkilere dahil etmek neler kazandırır? S. Hobden ve J. M. Hobson (Der.). M. L. Karadere (Çev.). Uluslararası ilişkilerin tarihsel sosyolojisi içinde (ss. 13-68). Sakarya: Sakarya Üniversitesi Kültür Yayınları.

Hobsbawm, E. J. (2014). Millet ve milliyetçilik. O. Akınhay (Çev.). İstanbul: Ayrıntı Yayınları. 


\section{insan \& toplum}

Hobsbawm, E. J. (2006). Geleneği icat etmek. E. J. Hobsbawm ve T. Ranger (Der.). M. M. Şahin (Çev.). Geleneğin icadı içinde (ss. 1-18). İstanbul: Agora Kitaplığı.

Jaffrelot, C. (2018). Bir milliyetçilik kuramı için. A. Dieckhoff ve C. Jaffrelot (Der.). D. Çetinkasap (Çev.). Milliyetçiliği yeniden düşünmek-kuramlar ve uygulamalar- içinde (ss. 23-82). İstanbul: Metis Yayınları.

Jaffrelot, C. (1998). Bazı ulus teorileri. J. Leca (Der.). S. Derman (Çev.). Uluslar ve milliyetçilikler içinde (ss.-54 68). İstanbul: Metis Yayınları.

Jensen, L. (2016). The roots of nationalism: Introduction. L. Jensen (Ed.). The roots of nationalism: National identity formation in early modern Europe 1600-1815 içinde. Amsterdam: Amsterdam Universty Press.

Kadıoğlu, A. (1999). Cumhuriyet iradesi demokrasi muhakemesi. İstanbul: Metis Yayınları.

Kalın, İ. (2013). Akıl ve erdem -Türkiye'nin toplumsal muhayyilesi-. İstanbul: Küre Yayınları.

Karadağ, H. (2005). Made in Europe: Türkiye için özel imalat çok kültürlülük. M. Ç. Özdemir (Der.). Çokkültürlülük ve Türkiyelilik içinde (ss. 44-50). Ankara: Tekağaç Yayınları.

Karakaş, M. (2007). Türk ulusçuluğun inşası. Ankara: Elips Kitap.

Kerestecioğlu, Ö. (2016). Milliyetçilik. H. B. Örs (Der.). 19. yüzyıldan 20. yüzyıla modern siyasal ideolojiler içinde (ss. 307-350). İstanbul: İstanbul Bilgi Üniversitesi Yayınları.

Kohn, H. (1929). A history of notionalism in the East. Londra: Routledge.

Kohn, H. (1995). Nationalism, its meaning and history. Princeton: D. Van Nostrand Company.

Koyuncu, A. A. (2018). Kuruluşundan Arap Baharına Suriye milliyetçilik ve ulus inşası. İstanbul: Sude Yayınları.

Kymlicka, W. (2015). Çokkültürlü yurttaşlık. A. Yılmaz (Çev.). İstanbul: Ayrıntı Yayınları.

Liakos, A. (2008). Hellenism and the making of modern Greece: Time, language, space. K. Zacharia (Ed.). Hellenisms. culture, identity and ethnicity from antiquity to modernity içinde (ss. 201-236). Aldershot: Ashgate.

Liakos, A. (2008a). Dünyayı değiştirmek isteyenler, ulusu nasıl tasavvur ettiler? M. Erol (Çev.). İstanbul: İletişim Yayınları.

Llobera, J. R. (1998). The concept of the nation in french social theory: The work of Dominique Schnapper. Nations and Nationalism, 4- (1), 113-21.

Mbembe, A. (2019). Zenci aklın eleştirisi. Ö. Arasan-Simon ve V. Çandar (Çev.). İstanbul: İletişim Yayınları.

Mills, C. W. (2007). Toplumbilimsel düşün. Ü. Oskay (Çev.). İstanbul: Der Yayınları.

Nairn, T. (2015). Milliyetçiliğin yüzleri -Janus'a yeni bir bakış-. S. Kırdar ve M. Ratip (Çev.). İstanbul: İletişim Yayınları.

Nandy, A. (1987). Cultural frames for social tarnsformation: A credo. Alternatives, 12(2), 113-116.

Nandy, A. (1994). The illegitimacy of nationalism. Delhi: Oxford University Press.

Özdemir, Ç. (2005). Çokkültürlülük ve Türkiyelilik. Ankara: Tekağaç Yayınevi.

Özensel, E. (2013). Doğu toplumlarında ve Türkiye'de birlikte yaşama arayışı: Çokkültürlülük mü? Yoksa yeni bir model mi? Akademik Incelemeler Dergisi, 8(3), 1-17.

Özkırımlı, U. ve Sofos-Spyros, A. (2013). Tarihin cenderesinde Yunanistan ve Türkiye'de milliyetçilik. S. Tekin-Özsakınç (Çev.). İstanbul: İstanbul Bilgi Üniversitesi Yayınları.

Özkırımlı, U. (2013). Milliyetçilik kuramları. Ankara: Doğu Batı Yayınları.

Renan, E. (2016). Ulus nedir? G. Yavaş (Çev.). İstanbul: Pinhan Yayıncılık.

Reus-Smith, C. (2015). Tarih fikri ve fikirlerle tarih. S. Hobden ve J. M. Hobson (Der.). M. Lüleci-Karedere (Çev.). Uluslararası ilişkilerin tarihsel sosyolojisi içinde (ss. 177-204). Sakarya: Sakarya Üniversitesi Kültür Yayınları. 
Said, E. S. (2017). Şarkiyatçllık. B. Ülner (Çev.). İstanbul: Metis Yayınları.

Shils, E. (1957). Primordial, personal, sacred and civil ties. British Journal of Sociology, 8-(2), 130-45.

Smith, A. (2017). Etno-sembolizm ve milliyetçilik. B. Firuze-Çallı (Çev.). İstanbul: Alfa Yayınları.

Smith, A. (1996). Nationalism and historians. G. Balakrishnan (Ed.) Mapping the nation içinde (ss. 175-197) London: Verso Press.

Spencer, P. ve Wollman, H. (2020). Milliyetçilik. K. Kelebekoğlu (Çev.). İstanbul: Yeni insan Yayınevi.

Szulc, L. (2017). Banal nationalism in the internet age: Rethinking the relationship between nations, nationalism and the media. M. Key, M. Antonsich (Ed.). Everyday nationhood: therising culture, identity and belonging after banal nationalism içinde (ss. 77-54). London: Palgrave Macmillan.

Şan, M. K. (2020). Çokkültürlülük. T. Erdem (Ed.). Milliyetçilik içinde (ss. 127-107). Antalya: Otorite Yayınları.

Taylor, C. (2004). Modern social imaginaries. Duke: Duke Univesity Press.

Tekin, S. ve Çemrek, M. (2020). Milliyetçilik kuramları. Milliyetçilik içinde (ss. 255-264). Antalya: Otorite Yayınları.

Türk Dil Kurumu. (1994). TDK sözlüğ̈̈. Ankara.

Wallem, G. (2017). The name and the Natioan: Banal Nationalisms and name change practices in the context of co-ethnic migration to germany. M. Key, M. Antonsich (Ed.). Everyday nationhood: therising culture, identity and belonging after banal nationalism içinde (ss. 96-77). London: Palgrave Macmillan.

Wagner, P. (1996). Modernliğin sosyolojisi - özgürlük ve cezalandırma-. M. Küçük (Çev.). İstanbul: Sarmal Yayınları.

Wendt, A. (2016). Uluslararası siyasetin sosyal teorisi. S. G. Ihlamur-Ünal (Çev.). İstanbul: Küre Yayınları.

Wolf, E. R. (2019). Avrupa ve tarihsiz halklar. H. Çalışkan (Çev.). İstanbul: Türkiye İş Bankası Kültür Yayınları.

Zawadzki, P. (2018). Milliyetçilik, demokrasi ve din. A. Dieckhoff ve C. Jaffrelot (Der.). D. Çetinkasap (Çev.). Milliyetçiliği yeniden düşünmek -kuramlar ve uygulamalar-içinde (ss. 209-246). İstanbul: Metis Yayınları. 